\title{
Navigating the Turbulent Waters of School Reform Guided by Complexity Theory
}

\author{
DAVID G. WHITE AND JAMES A. LEVIN \\ University of California, San Diego (USA)
}

The goal of this research study has been to develop, implement, and evaluate a school reform design experiment at a continuation high school with low-income, low-performing underrepresented minority students. The complexity sciences served as a theoretical framework for this design experiment. Treating an innovative college preparatory program as a nested complex adaptive system within a larger complex adaptive system, the school, we used features of complex adaptive systems (equilibrium, emergence, selforganization, and feedback loops) as a framework to design and evaluate a strategy for school reform. We created an environment for change by pulling the school far from equilibrium using a strategy we call "purposeful perturbations" to disrupt the stable state of the school in a purposeful way. Over the four years of the study, several tipping points were reached, and we developed agent-based simulation models that capture important dynamic properties of the reform at these points. The study draws upon complexity theory in multiple ways that support improved education for low-achieving students. This research does not provide a blueprint for an education reform that can be duplicated elsewhere - instead it provides a guide to help others to navigate the turbulent waters of school reform, informed by complexity theory. The exact nature of "purposeful perturbations" will differ from setting to setting, but this technique for generating persistent change may apply more generally. This study provides an existence proof of a successful teacher-initiated educational reform and shows that complexity theory can only not just describe educational reform but can also productively guide it.

\section{Introduction}

While not all high school graduates go to college, for those students who do attend college, adequate academic preparation for college-level coursework and support for developing learning strategies facilitates a successful transition to a college. And even for those who do not go on to college, a sound academic preparation is required for many other career paths.

Yet many high school graduates, in particular racial/ethnic minority students and students from low-income families, have neither the academic skills nor learning strategies necessary for 
college success (Hurtado, Inkelas, Briggs, \& Rhee, 1997). The lack of college readiness by underrepresented racial/ethnic minority students and students from low-income families has implications for college enrollment (Jones, Yonezawa, Ballesteros, \& Mehan, 2002), and the likelihood of success for those who do go on to college.

According to an ACT report on college readiness (2010), "Students who are not ready for postsecondary education are less likely to enroll in college, more likely to need remedial coursework during their first year of college, less likely to succeed in their college courses, and less likely to earn a college degree" (p. 5). This is especially problematic for underrepresented racial/ethnic minority student and students from low-income families. Not only do gaps exist in college enrollment rates across racial/ethnic groups and annual family income ranges, but gaps in college degree completion rates also exist across these groups and range of family incomes.

Students who graduate from high school unprepared for first-year college coursework often need substantial remediation. For example, of students who take remedial reading, more than half take four or more remedial reading courses and more than two-thirds also take remedial mathematics; of students who take remedial mathematics, more than 70 percent take two or more remedial mathematics courses (Adelman, 2004; Carey, 2004). Nationally, about one-third of high school graduates who enroll in college take remedial coursework. Underrepresented racial/ethnic minority students are almost twice as likely to take one or more remedial courses in college as Asian and White students (Parsad \& Lewis, 2003).

School reform efforts aimed at raising student achievement levels to address this lack of college readiness have been studied using a variety of theoretical frameworks (Elmore \& Burney, 1999; Fullan, 1999; Hubbard, Mehan, \& Stein, 2006; Stringfield \& Datnow, 2000).

In our research, complexity theory provided a lens for describing and explaining the reform process as it played out in the real-life context of a school with a majority of low-income, lowperforming underrepresented minority students. More importantly, complexity theory was also used as a framework for developing a strategy for creating conditions for educational change that started, rather than ended, with students and a strategy for navigating the often turbulent and unpredictable waters of school reform efforts.

\section{Literature Review}

In this research, the theory of complex adaptive systems provided a theoretical lens for describing the changes that occurred in a continuation high school for low-income, low-performing underrepresented minority students and also provided a guiding strategy for navigating the complex processes for implementing the changes.

\section{Complex Adaptive Systems}

Complex adaptive systems (Gell-Mann, 1994; Holland, 1998; Kauffman, 1995; Langton, 1996) represent a departure from traditional system models. According to Stacey (2007), complex adaptive systems (CAS) are made up of a large number of agents where each individual agent behaves according to a set of rules. These rules require individual agents, through their interaction with other agents; to adjust their actions to that of the other agents, forming what Stacey calls "population-wide patterns." In this sense, CAS differ from most other system models, 
which view systems at a macro level, in that CAS view systems at a micro level, through the local interactions of their agents.

While it may be difficult to characterize individuals in organizations such as schools as following one set of rules, they do share certain common features that qualify them as CAS.

Equilibrium

CAS have the capacity for transformational change. However, for new structures and patterns of behavior to be created, a CAS must be far from equilibrium, otherwise changes will be temporary (Mischen \& Jackson, 2008).

For CAS that are in a stable state, equilibrium needs to be disrupted in order to create conditions for change. Introducing perturbations into a system that push a stable system far from equilibrium may result in the emergence of a new system through interactions of its internal elements (Morrison, 2002).

Capra (1997) describes how systems can change when they are "pushed" far from equilibrium towards what Brown and Eisenhardt (1998) call the "edge of chaos." When CAS are pushed far from equilibrium they can encounter bifurcation points, what Capra calls forks in the road, leading to self-organization, the emergence of new forms, or dissipation, where systems revert to a variation of their initial stable state. At bifurcation points systems have the possibility to develop in several different ways, and the new form cannot be predicted.

Self-Organization and Emergence

A key feature of all CAS is that they are self-organizing systems. Self-organizing systems exhibit a nonlinear interconnectedness of system components resulting in feedback loops. According to Stacey (2007), these feedback loops "take the form of agents interacting locally according to their own principles, in the absence of an overall blueprint for the system they form" (p. 196). These self-organizing local interactions produce emergent population-wide patterns of behavior. Emergence describes the patterns of interaction through the behavior of interconnected elements that both adapt to and construct their environment.

Emergence is the partner of self-organization (Morrison, 2002). Since change emerges over time interdependently, it is not possible to determine outcomes in advance with any certainty. In CAS such as organizations, individuals are interdependent - none of them can simply choose what will happen to all of them. According to Stacey (2007), "what happens to all of them will emerge in the interplay of their intentions and no one can be in control of this interplay" (p. 239). Strategy for change in some sense emerges in the interplay of individual intentions.

\section{Feedback Loops}

Since change in CAS occurs through local interactions, feedback loops exist between interacting elements of a system (Marion, 1999). Mason (2009) states that: "A central concern of complexity theory is on the relationships among the elements or agents that constitute a particular and sufficiently complex environment or system" (p. 118).

CAS's reliance on feedback loops means that agents need to be connected, creating social networks. Daly (2010) defines a social network as: "a group of actors who are connected to one another through a set of different relations or ties" (p. 4). In organizations, individuals within a 
social network are interdependent since they share the same social network. Because of the connections between individuals, social network analysis provides a tool for studying the structure of the relationships between individuals in organizations. Cilliers (2001) and Stacey (2001) argue that one way to understand CAS is to study the patterns of interactions within a network.

In organizations, where individuals can change or evolve, social networks can change or evolve. The actions of individuals not only move along feedback loops, they can also change these loops. In organization science, studies of how social networks change provide insights for scholars who view organizations as CAS (Anderson, 1999) and may be used to develop effective strategies for change (Daly, 2010).

\section{Research Approach}

Although complexity theory has its origins in the natural sciences (Kauffman, 1995; Mitchell, 2009), over the last few decades it has been also increasingly used in the social sciences (Allen, 2001; Brown \& Eisenhardt, 1998; Wheatley, 1999). Recently, complexity theory has been applied to school reform efforts (Levin \& Datnow, 2012a, 2012b; Maroulis et al., 2010; Mason, 2009; O'Day, 2002; Sui, 2008).

Studies that examine school reform efforts through the lens of complexity theory tend to rely on computer simulations. For example, Maroulis et al. (2010) used computer simulation methods to examine the inter-organizational dynamics that gave rise to organizational change across a large urban district. Stacey (2007) argues that complexity scientists use computers to simulate the behavior of CAS because "it is not possible to experiment with living systems in real-life situations" (p. 196).

While complexity theory has been used to describe and explain school reform efforts, to date, no studies have looked at how complexity theory could be used as a theoretical framework for designing and implementing a strategy for school reform.

\section{Methodology}

A design research experiment was conducted to create conditions for transformational change to occur at a continuation high school with low-income, low-performing underrepresented minority students, to produce data that would enable us to draw warranted conclusions about school reform and what contributes to it (White, 2011; White \& Levin, 2013). We chose a design experiment approach because the school reform was evolving over the course of our study, and this approach provided the flexibility to allow for that evolution.

Cobb, Confrey, diSessa, Lehrer, and Schauble (2003) state that "design experiments are conducted to develop theories, not merely to empirically tune 'what works'" (p. 9). According to Mehan (2008), who refers to this as design research, this approach is useful in educational settings because it focuses on improving practice while at the same time building theory. Mehan argues that design research attempts to go beyond writing a description of "what's going on here" ( $p$. 84).

Design experiments have a number of characteristics ideal for this setting (Cobb et al., 2003; Collins, 1999; Schoenfeld, 2006). First, design experiments are set in the messy situations that 
DAVID WHITE AND JAMES LEVIN

characterize real-life contexts. Design experiments therefore constitute a means of addressing the complexity found in educational settings. Second, unlike the design of quantitative-analytical experiments where one variable is changed while all other variables are held constant, in design experiments there are many variables that vary. Third, design experiments must be flexible, that is, they must be open to design revision. Design modifications are made based on what emerges. "The result is an iterative process featuring cycles of invention and revision" (Cobb et al., 2003, p. 10). Fourth, design experiments are primarily concerned with developing theory in local contexts.

\section{Research Setting}

The setting selected for this study was Gonzago High School (GHS) (all the school and district names used in this paper are pseudonyms). GHS, a continuation high school, opened its doors in 1921. Continuation education is a high school diploma program designed to meet the needs of students 16 through 18 years of age who have not graduated from high school, are not exempt from compulsory school attendance, and are deemed at-risk of not completing their education, according to California Education Code, 48400-48438 (California Department of Education, 2013).

Located on the campus of St. Diaz City College (SDCC), in a large urban city in Southern California, GHS operates in the St. Diaz Unified School District (SDUSD) on a traditional school year (10 month) calendar. GHS serves as both a dropout prevention and dropout recovery school. Students, referred to GHS through SDUSD district counselors, are typically 16-17 years old, are seriously credit deficient often having 10 or fewer credits, and are unable to catch up to their graduating class.

On average, GHS serves approximately 450 students, 350 in its continuation education program and 100 students in its independent study program. These numbers varied month by month. Virtually all students who enroll at GHS are referred because they are at risk of dropping out of school. During the 2006-2007 school year, when this study began, fifteen percent of GHS's students were pregnant and/or parenting.

GHS has a predominately low-income, minority student population. For the 2006-2007 school year, the student population was $76 \%$ Hispanic and $14 \%$ African American. Approximately 29.1 percent of GHS's student (112 students) were designated English Learners (ELs). Of the school's ELs, over 90 percent spoke Spanish at home. Student eligibility for free or reduced-price meals, based on household size and income, is one measure of low income among a school's families. For the 2006-2007 school year, 69.7 percent of GHS students (268 students) were eligible to participate in the free and reduced-price lunch program and thus were identified for support from the Title 1 Program. These demographics remained stable through the period of this study.

\section{Research Design: Complexity Theory as a Framework for School Reform}

In our research, the theory of CAS, with features of equilibrium, emergence, self-organization, and feedback loops provided both a strategy for school reform and a theoretical lens for analyzing the change process as it evolved. One feature of CAS, equilibrium, requires that in order for 
change to occur, a system must be in a state far from equilibrium. The equilibrium of systems in stable states must be disrupted if one wishes to create conditions where real transformational change can occur. While disrupting the equilibrium of a complex adaptive system does not need to be by design, the efforts to push GHS far from equilibrium were in fact by design - what we call "purposeful perturbations".

Specifically, an innovative college program, Academic Commitment Creates Empowered Successful Students (ACCESS), created to academically prepare GHS students for college, was viewed as a "nested" CAS within a larger CAS, GHS. In the process of implementing this program, purposeful perturbations were introduced that disrupted the school's stable state and had a major influence on the changes that occurred at GHS from February of 2007 through March of 2011 (White, 2011). While we developed the concept of "purposeful perturbation" in 2010, Beabout (2012) provides a helpful analysis of the difference between the related concepts of perturbance and turbulence, which helps to clarify our concept.

During this research study the first author was teaching chemistry and mathematics at GHS. Since the purpose of this research study was not only to describe and explain the changes that occurred during this study but also to create conditions necessary for transformational change at GHS by design experiment, the positionality of the first author was that of change agent. In that sense he was an active participant, a fundamental feature of design experiments.

The first author remained conscious of his positionality as he made choices of who to interview, conscious of his positionality when he conducted and transcribed audio-recorded interviews, and conscious of his positionality when he analyzed data from school documents and records and data from interviews. He attempted to avoid imposing his own views upon this research study by backing up any claims with transcripts of interviews and copies of school documents and records that were used in this study.

All of the staff of the school gave their informed consent to participate in this study, and all

of the students interviewed assented to participate with written consent provided by the parents or guardians of those under the age of 18 years.

\section{Data Collection}

There were two main sources of data in this study: school documents and records, and seventeen individual audio-recorded interviews.

The following school documents and records were collected:

- The ACCESS action plan

- College assessment test results

- Records of SDCC classes taken by GHS students

- School Accountability Report Card (SARC)

- Expected School-wide Learning Results (ESLRS)

- Western Association of Schools and Colleges (WASC) self-study report

- program improvement proposal

- Joint Diploma Program (JDP) documents and records

- City Middle College (CMC) documents and records

- SDCC grants for CMC and the Tech Prep Development Program (TPDP)

- The Memorandum of Understanding (MOU) between GHS and SDCC 
DAVID WHITE AND JAMES LEVIN

- Standard operating procedures for enrolling GHS students in SDCC classes

Individual audio-recorded interviews

Between April of 2009 and September of 2009, the first author conducted audio-recorded interviews. Interview participants included:

- The principal of GHS

- Three GHS guidance counselors

- Four non-ACCESS teachers

- Three ACCESS teachers

- Three non-ACCESS students

- Three ACCESS students

The interview scheduling was flexible. Interviews were selected as a cross-section of the staff and students at the school, and scheduled based on the most convenient time for each participant. All participants invited to participate agreed and were interviewed. The interviews took place in a private location convenient for the participant. Each interview was audio recorded. General topics covered in the interviews included respondents' background in education, respondents' views on ACCESS and the other GHS academic programs, respondents' views about being located on a college campus, and each respondent's social network within GHS and with SDCC. Audio-recorded interviews were transcribed using InqScribe, a transcriptional software program that supports digital video or audio analysis (InqScribe, 2011).

\section{Data Analysis}

Research methods in this study consisted of two principal activities: review and analysis of school documents and records, and review and analysis of individual audio-recorded interviews (White, 2011). A technique called Artifact Elicited Response, designed to provide a new dimension for conducting audio-recorded interviews, was used to provide a detailed picture and a description of respondents' network structures within the school's learning community.

Analysis of data from documents and records and audio-recorded interviews served two purposes. Our analysis of research materials was informed by our orienting research questions:

If an innovative program, with the primary goal of academically preparing low-

performing students for rigorous college coursework, is implemented at a continuation high school:

1. What structures and patterns of behavior around academic preparation for college emerged as the program evolved?

2. In what ways did these emerging structures and patterns of behavior impact the organizational structure of the school's learning community?

Data analysis also served to allow design modifications to be made based on what emerged as a result of a particular purposeful perturbation. In this sense, the experimental design of the research was an iterative process. Design modifications were made based on what emerged as a result of each purposeful perturbation. Since outcomes from perturbations were emergent, design modification was also a responsive process. 


\section{Results and Analysis}

\section{GHS's Initial Stable State, 2006-2007}

Effective school reform efforts result in transformational change. By transformational change, we mean a shift in the school's organizational structure and culture resulting from a change in the underlying strategies and processes that were used in the past. In CAS such as schools, transformational change ultimately involves the creation of "new contexts" that challenge the existing organizational structure by creating conditions where the stable state of the system no longer works. In order to create a context in which appropriate forms of change could occur, it was necessary to understand the existing context, the stable organizational state that existed at GHS in 2007.

GHS moved to a new facility located on the campus of St. Diaz City College (SDCC) in September of 1998. As early as the 2000-2001 school year, GHS's espoused goals were to increase student retention rates, increase graduation rates, provide GHS students with a college experience and increase the number of GHS graduates who went on to enroll in college courses.

Through the cooperation of SDUSD and the St. Diaz Community College District (SDCCD), GHS developed joint programs with SDCC, the Joint Diploma Program (JDP) and City Middle College (CMC) to help achieve these goals.

The JDP, a partnership between the St. Diaz Community College District Continuing Education Centers (SDCE) and SDUSD's Adult Education Office of Extended Learning Opportunities, was designed specifically to offer older students (ages 17-19) who were severely credit deficient an alternative diploma. Students at alternative schools such as GHS could earn an "option 2" high school diploma through the JDP. The option 2 diploma required high school students to earn 24-credits rather that the 44-credits required for high school graduation in the SDUSD and more generally, across the state of California.

In 1994, SDCC and GHS entered into a partnership that provided GHS students with the option to enroll in specific courses at SDCC in order to fulfill the JDP option 2 requirement of successfully completing one college course. Moving to the campus of SDCC facilitated GHS students' ability to meet the requirement of the JDP for completing a college course.

City Middle College (CMC), a partnership program between GHS and SDCC, was a job skills program developed under the auspices of SDCE and GHS that opened in February of 2000. According to the initial CMC grant proposal (1999):

The overall project goal has been to enhance college and career options for high potential, low achievement students who are older, and more at risk of not completing high school diploma requirements than the usual middle college student. ... It is understood that the 75 students participating in the CMC Bridge Project will be more difficult to serve than the traditional middle college student. (p. 3)

The CMC grant application also stated that the intended target student population were GHS students already enrolled in the JDP and seventeen-and-a-half to nineteen years of age, who were severely credit deficient, seriously at risk of dropping out of school, not completing their high 
school diploma and entering the workplace without the skills required for securing quality employment. These were the same criteria as for the JDP.

By 2006, both the JDP and CMC were instrumental in helping GHS meet its goals. There was a decrease in the number of students dropping out of GHS, a higher percentage of GHS students were earning a high school diploma, more than half of all GHS students were enrolling in at least one college course, and many GHS graduates were enrolling in classes at SDCC post high school.

However, a closer look at these achievements revealed underlying problems. First, although there had been a steady increase in the number of GHS students earning a high school diploma, that increase coincided with an increase in the percentage of 24-credit, option 2 diplomas awarded GHS graduates. This had implications for those students planning to attend college since students earning an option 2 diploma were less likely to be academically prepared for rigorous college coursework. When students were asked to describe the JDP, they gave one response consistently. All students interviewed stated that it is better to go for the 44-credit diploma. Their reason was because the 44-credit diploma would prepare them for college. For example, when the first author asked RR, a GHS senior, about the JDP, he got the following response:

DW: Should I do the Joint Diploma Program?

RR: Joint Diploma Program allows you to get twenty-two credits instead of the regular forty-four. That way you don't have to do certain maths, or English or Science, but it ends up being detrimental to you because you're just cutting off classes that ultimately you're going to need anyway.

Second, while the JDP option 2 diploma was designated for older, severely credit-deficient students, a review of school records showed that many younger students, who did not meet JDP age and credit deficiency requirements, were being enrolled in the option 2 diploma. When the first author asked JW, one of the GHS counselors to talk about one of his students, JW told him about a 16 year-old girl whose goal was to earn an option 2 diploma.

DW: So tell me about one of your students...and how you're counseling them

JW: OK. I have one young lady in mind right now. She is 16 years old going on 17 . She came to me with about five credits. She has not passed either of the two high school exit exams. I think she's leaning towards going for an option 2 diploma but at the moment she's not eligible for the option 2 diploma because she hasn't passed either CAHSEE. But that's what she's shooting for.

By the 2006-2007 school year, 76 percent of all diplomas earned by GHS graduates were option 2. GHS was well on its way to achieving its espoused goal of "becoming an all joint diploma school" (CMC Grant, 1999, p. 2).

Third, to fulfill the JDP option 2 requirement to successfully complete a college course, virtually all GHS students were enrolling in non-degree track courses at SDCC instead of degreetrack courses. Degree-track courses are transfer-level academic courses that are necessary to earn a baccalaureate degree in an academic discipline at a four-year college or university. One example of a student taking a college class to fulfill a JDP option 2 diploma requirement came up during an interview with an eighteen-year old senior, JC.

DW: So are you taking any college courses? 


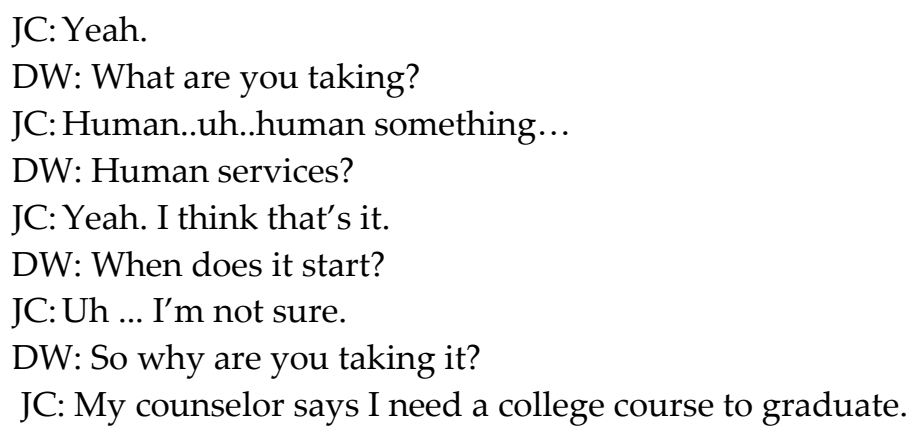

Finally, despite the fact that most GHS students took at least one college course when this study began, not one GHS graduate had earned a Certificate of Achievement, Certificate of Completion or an Associate Degree that led to a vocational career, much less transferred to a four-year college or university.

For the first eight and one-half years that GHS was on the campus of SDCC, academic preparation for college was neither one of GHS's goals nor one of its accomplishments. So while each of the individual goals were laudable, the way in which the cluster of goals was accomplished left GHS graduates without the ability to continue their education in higher education.

\section{Purposeful Perturbation One: Providing Disconfirming Evidence by Raising the Level of Student Academic Performance}

From September of 1998, through the 2005-2006 school year, there was an existing state of dynamic equilibrium at GHS with regard to academic performance that manifested itself in low academic expectations of students by the GHS staff, low-levels of academic performance by GHS students, and low self-expectations of academic performance by the students. While individual student performance levels varied, there was an upper level of academic performance beyond which students did not go. Virtually no GHS graduates had the skills necessary for success in rigorous college coursework.

To address this problem, an innovative college prep program, Academic Commitment Creates Empowered Successful Students (ACCESS), was introduced at GHS in February of 2007 to arm GHS students with the skills and knowledge that might help them academically prepare for college (White, 2011). The mission of ACCESS has been to prepare students for post-secondary education through rigorous college-preparatory coursework with a primary focus on improving reading, writing, and math skills, and to support a school culture that fosters school team spirit, and students' emotional health.

Many of GHS's teachers, counselors, and administrators did not think GHS students were capable of higher education. So this program caused trouble because it confronted the existing everyday practices and belief systems of the individuals, and groups of individuals, which defined the organizational structure of GHS. Despite the support of GHS's principal, ACCESS experienced resistance from the beginning. According to the GHS English language learner support teacher:

When the ACCESS program began, it was greeted with open skepticism and hostility from much of the staff. The common attitude was that "these kids" were generally incapable academically, 
were not going to college, did not come from families that would support them going to college,

and were unwilling to expend the extra time and energy to improve academically.

While the primary goal of ACCESS was to raise the academic performance of a small group of students to a level necessary for success in rigorous college courses, a secondary goal was to create the kind of disconfirming evidence that would challenge the belief systems of GHS staff members that put GHS students on a fast track to a high school diploma without adequately preparing them for post-secondary education.

Beginning in 2007, ACCESS students took college assessment tests in math and English at the end of the school year. Assessment test data served two purposes. First, test results provided feedback about how well ACCESS was academically preparing students for college. Second, test results provided hard data that challenged the beliefs of GHS staff.

The Success of ACCESS Math: Over the five-year period from 2006 though 2011, ACCESS math had achieved more success in academically preparing GHS students for college than ACCESS English. While both ACCESS Math and English started with eight students and one class for each subject, by May of 2010, ACCESS Math offered more classes, enrolled more students and had more students testing at the transfer level than English on college assessment tests. There are a number of factors that contributed to the success of ACCESS Math students.

First, ACCESS elementary algebra and intermediate algebra math courses were articulated with SDCC elementary algebra and intermediate algebra math courses. Textbooks, adopted by SDCC in these subjects, were used as the textbooks for ACCESS math. This was done in an attempt to strengthen the view in the eyes of GHS students who were enrolled in ACCESS Math that these were indeed college prep classes and that successfully completing these courses would increase their chances of testing out of these courses on the college math assessment test.

Second, by the 2007-2008 school year the majority of GHS ACCESS students were enrolled in ACCESS math for the entire year. The majority of returning students who completed the first year of ACCESS math continued in ACCESS math during the following school year. For those returning students, ACCESS could provide them with two years of college prep math.

Third, we viewed the relationship between academic expectations and student academic performance as a matter of reciprocal causality. Teachers' academic expectations influence levels of student academic performance. Conversely, levels of student academic performance influence teachers' academic expectations. We represent these not as cause-effect relationships, but as a feedback loop (as shown in Figure 1). In the first year of ACCESS math, the academic expectations for ACCESS students were to successfully complete the ACCESS elementary algebra course and test into intermediate algebra on the college math assessment test. When the majority of first year ACCESS Math students successfully completed elementary algebra and tested into intermediate algebra, the first author raised his academic expectations. In the second year of ACCESS Math, his goal was to get some students through both elementary and intermediate algebra ACCESS courses and test into transfer-level math on the college math assessment test. This "raising the bar" of academic expectations and the increasing level of academic performance in math resulted in 24 ACCESS students taking the college math assessment test in May of 2010, with 13 students testing into transfer-level math and 11 students testing into intermediate (see Figure 2). 


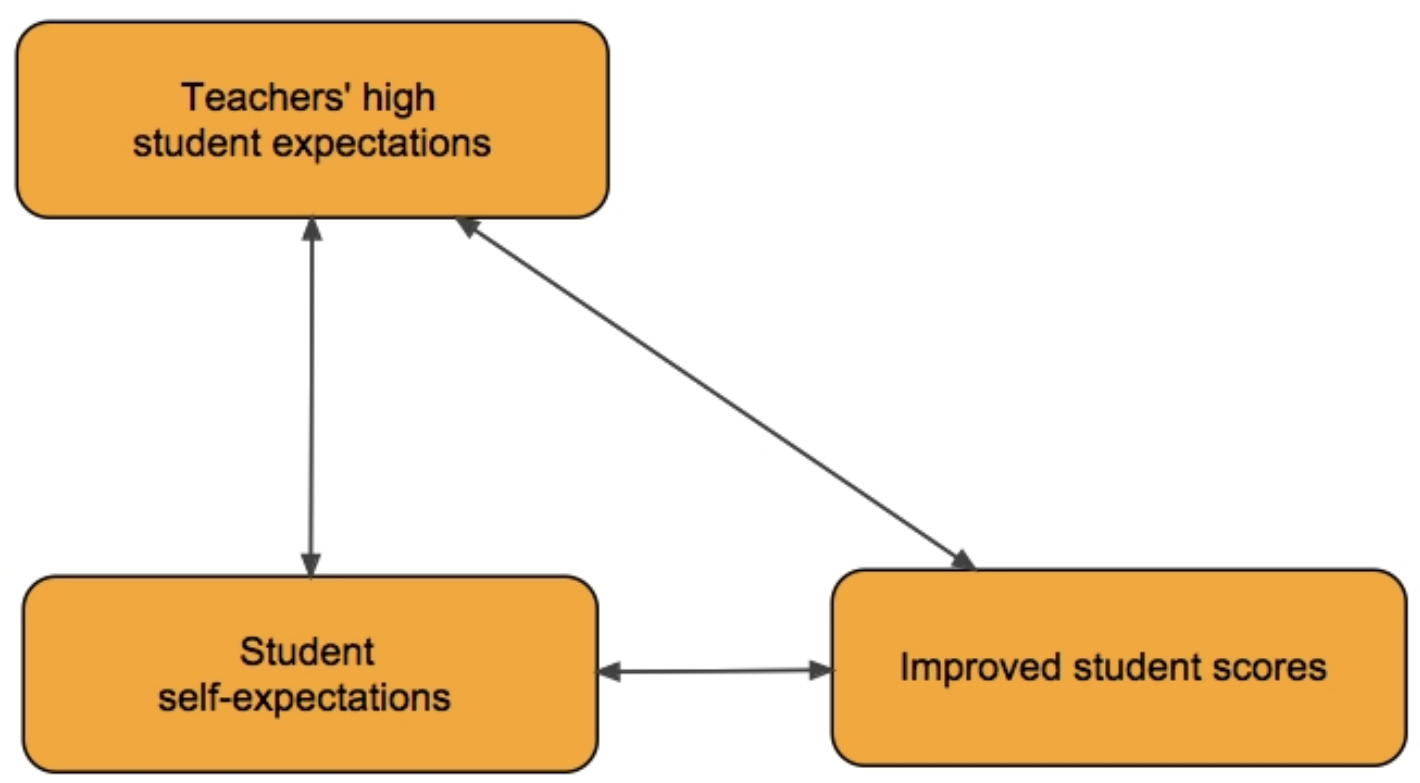

Figure 1: Teacher-Student reciprocal causality feedback loop

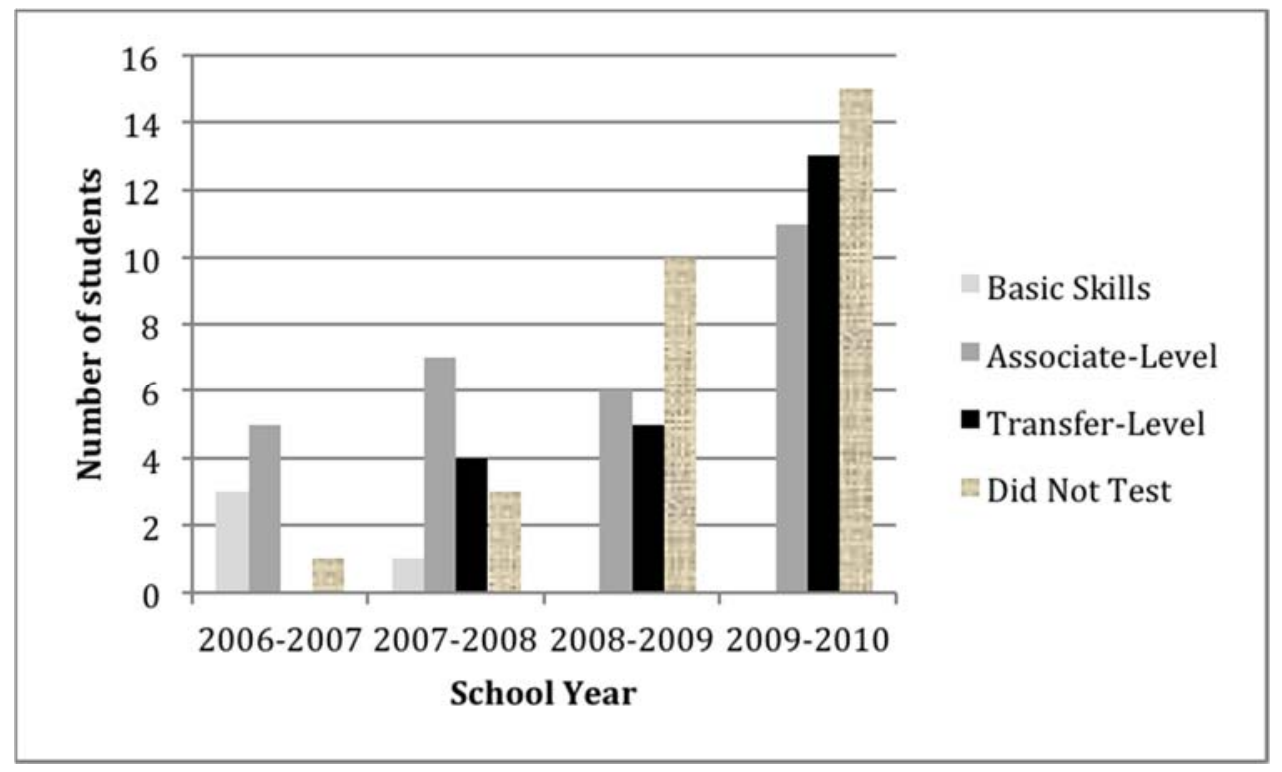

Figure 2: ACCESS college assessment test results for mathematics

A multi-mediator model of the first purposeful perturbation and the tipping point it led to

To better understand the ways in which the improvement in student scores on assessment tests impacted the expectations both of the students themselves and of the staff at GHS, we constructed several multi-agent computer simulation models. The models were constructed within NetLogo, a free multi-platform agent-based model-building environment developed by Wilensky (1999) and his colleagues at Northwestern University. 
DAVID WHITE AND JAMES LEVIN

In this multi-mediator modeling framework (Levin \& Datnow, 2012a, 2012b; Halter \& Levin, 2013; White \& Levin, 2013; Levin, 2015), the concepts in the domain being modeled are represented by labeled circles, each of which has an activity level that is partially determined by impact from other concepts within the model and partially determined by outside context. The activity level of each concept (represented as an orange circle) is indicated visually both by its size and the intensity of its color.

There are two ways in which a concept's activity level can be impacted by other concepts within a given model. A concept's activity level can be positively impacted by another concept within the model (indicated by a green arrow from that other concept).

The higher the activity level of that other concept, the higher the activity level will be of the positively impacted concept.

A concept's activity level can be negatively impacted by another concept within the model (indicated by a red line with a bar at the end from that other concept).

The higher the activity level of that other concept, the lower the activity level will be of the negatively impacted concept.

This framework not only allows for positive and negative actions by one concept on another, but it also allows for interaction between two concepts (mutual actions), and for mediation among three or more concepts, as represented by a network of positive and negative directed connections among a set of concepts.

In addition, a concept can be impacted by context (everything outside the domain that is being modeled), and part of the model is specified by the levels of activity of each concept that is supported by its context.

All of these impacts occur in parallel, and so activity levels flow throughout a given model, based on the connections among the concepts and the impact from context. This multi-mediator framework has been used to represent learning at several levels of scale, including organizational learning (reform) at the district level (Levin \& Datnow, 2012a, 2012b) and individual learning (Halter \& Levin, 2013; Levin, Jacobson, \& Markauskaite, 2014). In this paper, we will represent learning at the school level, the changes that flowed from the ACCESS reform.

Figure 3 captures some aspects of the first purposeful perturbation. It focuses on the role that improving student scores on community college placement examinations played in changing teacher expectations of student academic capabilities. 


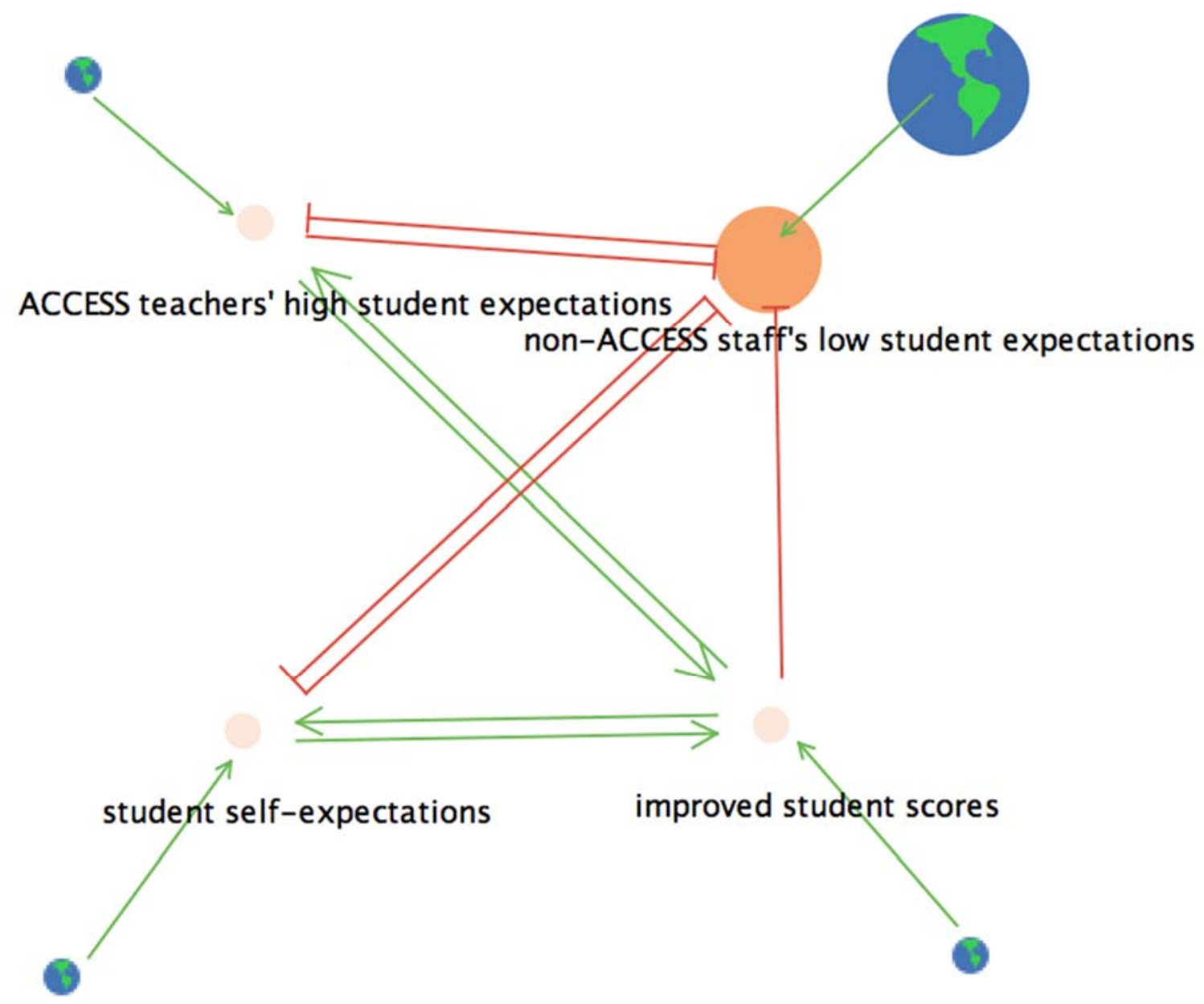

Figure 3: A multi-mediator model of the change in teacher expectations of low student academic performance, available online at:

https://drive.google.com/file/d/0B24EChPrG7E SDA4dWZ2UWVoUzQ/view?usp=sharing

There are four concepts in this model: the student self-expectations, improved student scores, non-ACCESS staff's negative expectations about the students, and the ACCESS teachers' positive expectations of students.

Initially student self-expectations and academic performance (as measured by student scores) are low, as impacted by the negative expectations of the non-ACCESS teachers and other staff at the school. As the ACCESS teachers' positive expectations of the student increase, initially there is no change, but eventually a tipping point is reached where the student expectations and scores increase, changing the expectations of the non-ACCESS staff members. This model captures the non-linear nature of change that occurred during this phase of the ACCESS reform. This is illustrated in the four panels of Figure 4.

Panel D of Figure 4 shows that after the tipping point is reached, there is a persistent change in the state of the model, even after the initial purposeful perturbation passes. This kind of persistent change is a hallmark of successful educational reform. Figure 3 is a specific implementation of the kinds of feedback loops referred to more generally in Figure 1. Unlike Figure 1, which is just 


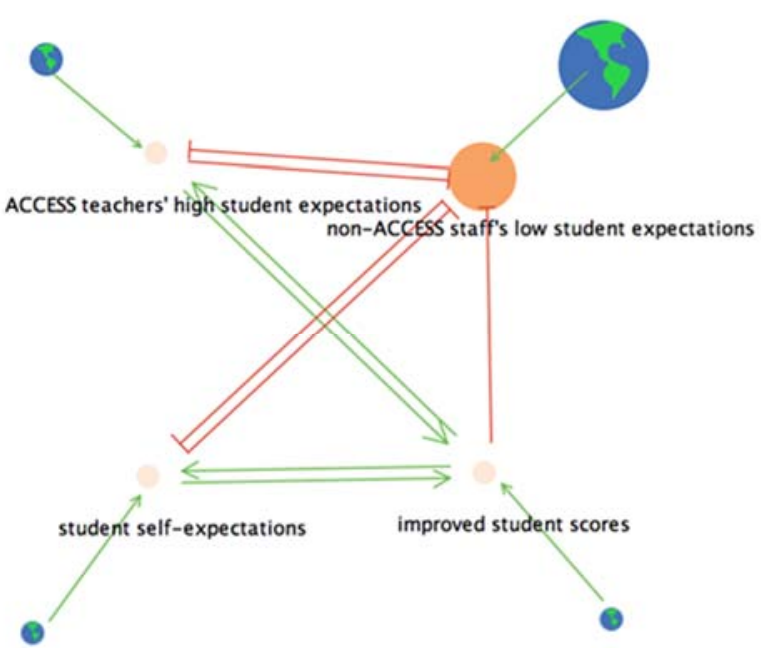

(A)

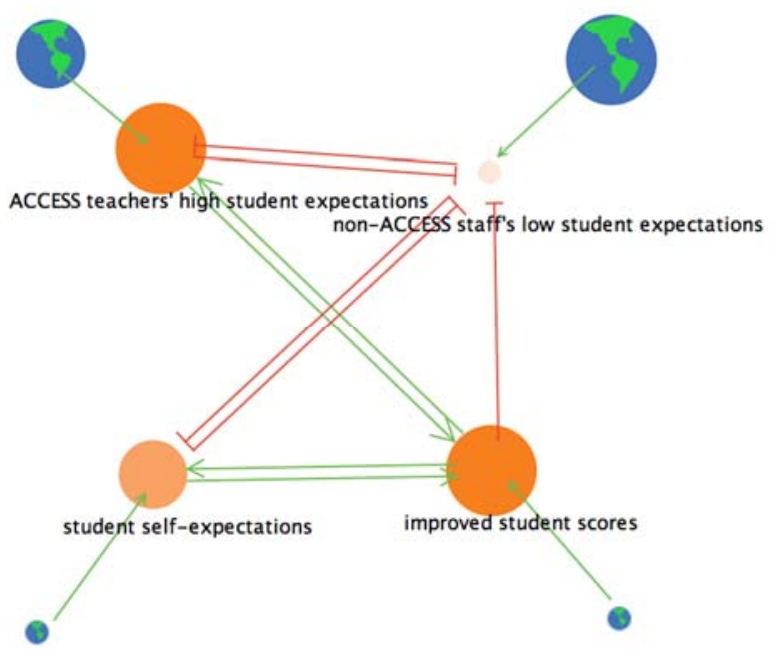

(C)

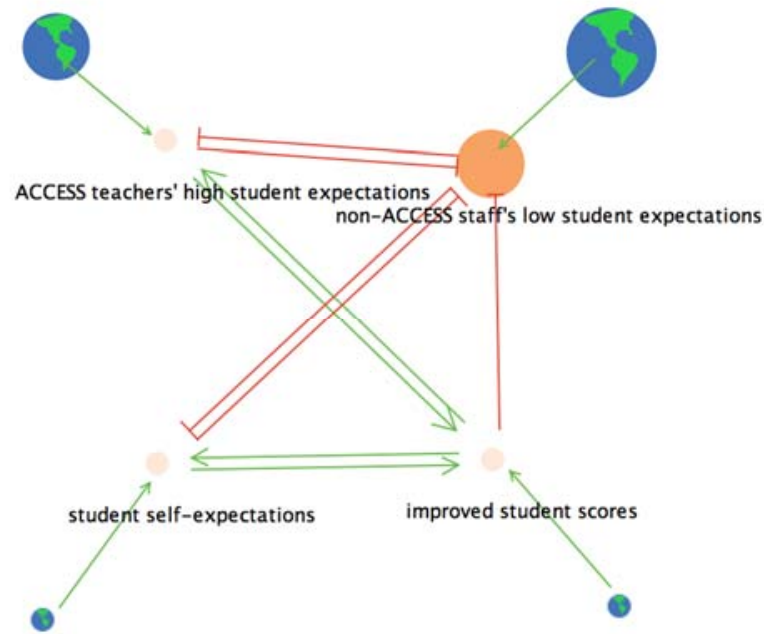

(B)

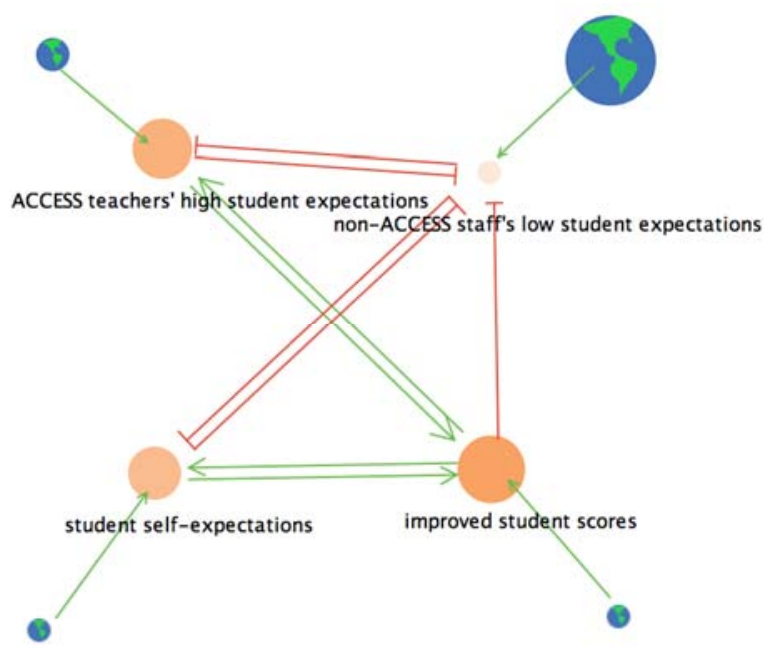

(D)

Figure 4: Four snapshots of the model shown in Figure 3, as the activity level of the contextual support for the ACCESS teachers' expectations (the blue globe in the upper left corner of each panel) increases through a tipping point (from panels A through $\mathrm{C}$ ) and then deceases to the initial level (in Panel D).

a graphic representation of feedback loops, Figure 3 is both a graphic representation of those feedback loops and also a visualization of a simulation model with the dynamic properties shown in the four panels of Figure 4.

This model was constructed based on the data that we collected, following the rubric described in Levin \& Datnow (2012a) and in Levin (2015). With this rubric, the first step is to identify the most important elements in the domain being modeled. These become the concepts in the model. The second step is to specify, based on the data, which of these elements have a positive impact on other elements and which have a negative impact. These are the directional links between the concepts. The third step is to identify, based on the data, the impact that 
everything outside of the domain being modeled has on each concept in the model. This model building rubric was used to construct the model in Figure 3 and the other models presented below in Figures 11, 12, and 16.

\section{A Second Purposeful Perturbation: The Creation of New GHS-SDCC Network Structure Connections and the Consequences of Competing Networks}

Raising levels of student academic performance did provide disconfirming evidence that challenged the academic expectations at GHS. When AV, a GHS guidance counselor, was asked if ACCESS had any impact on the school her response was:

AV: Now we are thinking beyond high school, we're thinking beyond the easiest way to get 'em through. Or let's just get them a diploma at all cost...we're thinking about preparing them for the next step.

However, initial efforts to disrupt the equilibrium of GHS, even in a purposeful way, were not sufficient to promote the kind of changes that were desired. That is, raising students' levels of academic performance did not result in changes in the patterns of behavior that determined the type of diploma GHS students earned, and which college courses they enrolled in. The vast majority of GHS graduates were still earning a 24-credit, option-2 diploma rather than the 44credit diploma required by the St. Diaz Unified School District (SDUSD) at comprehensive high schools. Furthermore, GHS students were still being advised to enroll exclusively in non degreetrack courses at St. Diaz City College (SDCC) by their high school counselors.

By the second year of ACCESS a few ACCESS students had raised their level of academic performance to qualify for enrollment in rigorous, degree-track college courses as evidenced by Math and English scores on college assessment tests taken at the end the regular school year (White, 2011). For GHS students who would be graduating in June of 2008, this meant that they had qualified to enroll in transfer-level college courses. However, for those continuing GHS students who had tested into transfer-level Math and English, this was problematic. By testing into transfer-level Math and English on college assessment tests, continuing students may have met requirements to enroll in transfer-level courses at SDCC but they were not being counseled to enroll in these kinds of college courses. The problem was further compounded by the fact that those students' level of academic performance in Math and English went beyond the level of courses offered at GHS.

To understand why ACCESS students, or for that matter, GHS students in general, were not enrolling in degree-track courses at SDCC, we needed to understand the existing network structure between GHS and SDCC and the relevant standard operating procedures that determined the stable patterns of behavior for enrolling students in college courses at SDCC. If we were going to develop an effective strategy for changing these stable patterns of behavior, we needed to understand what was going on and why.

Artifact Elicited Response Technique - Creating a Picture of GHS's Existing Network Structures:

The primary source of data we used to construct a picture of the network structures that existed within GHS and between GHS and SDCC came from interviews the first author conducted in 2009 with the GHS teachers, GHS counselors, and the GHS principal (White, 2011). During those audio-recorded interviews we wanted respondents to provide a detailed picture and description 
DAVID WHITE AND JAMES LEVIN

of their network structures at GHS and with SDCC. To accomplish this, we used an approach developed by the first author called "Artifact Elicited Response Technique" (White, 2011). Like Tobin's (1989) use of a video elicited response technique, the use of an artifact-elicited response technique was designed to provide a new dimension to conducting audio-recorded interviews.

The technique, as used during interviews, was to ask respondents to construct an artifact, in the form of a drawing, depicting their network structures within the school. Each respondent was provided with a magnetic white board and a set of magnetic squares with either a job title of a key GHS or SDCC staff member, a GHS department, or a GHS-SDCC program written on each square. Respondents were also provided with instructions to guide them in the construction of their network structures. Each respondent was given as much time as they needed to complete their drawing. The drawing was then used as a prompt to generate questions from me, and responses from the interviewee. Figure 5 shows a photograph of the artifact constructed by $\mathrm{CF}$, a GHS ACCESS science teacher.

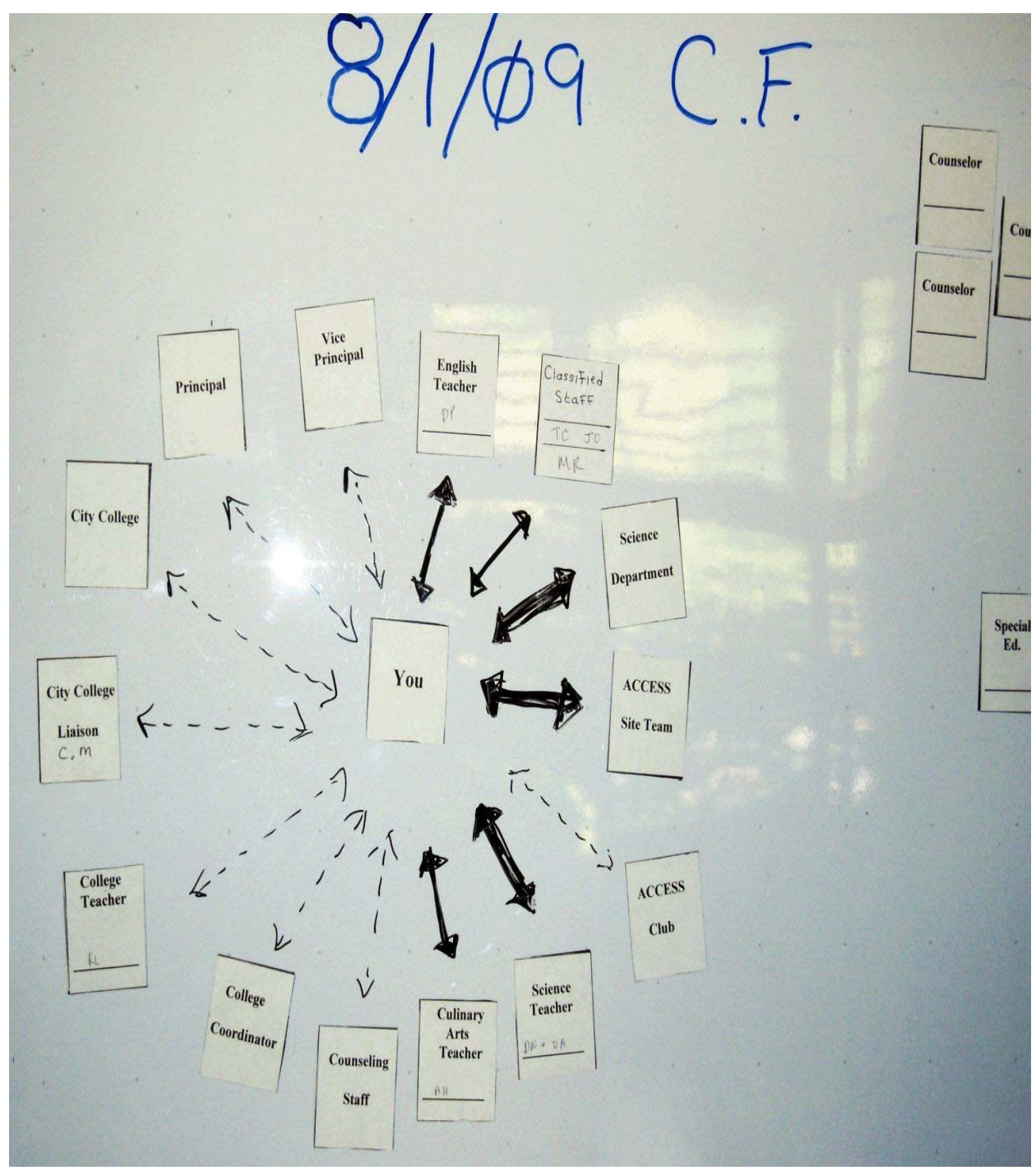

Figure 5: A white board representation of CF's network structure 
The first author used the Visual Understanding Environment (VUE, 2010) software to construct network structure diagrams based on each respondent's white board network structure drawing.

VUE is a concept and content mapping application developed by the Academic Technology group at Tufts University. Figure 6 shows the network structure diagram that the first author constructed using VUE based on $\mathrm{CF}^{\prime}$ s white board drawing shown in Figure 5. A thicker solid line represented a strong connection, a thinner, solid line represented a medium connection and a broken line represented a weak connection. No line represented the absence of a connection. Connections were represented by either one-way arrows or two-way arrows depending on how connections were represented on a respondent's drawing.

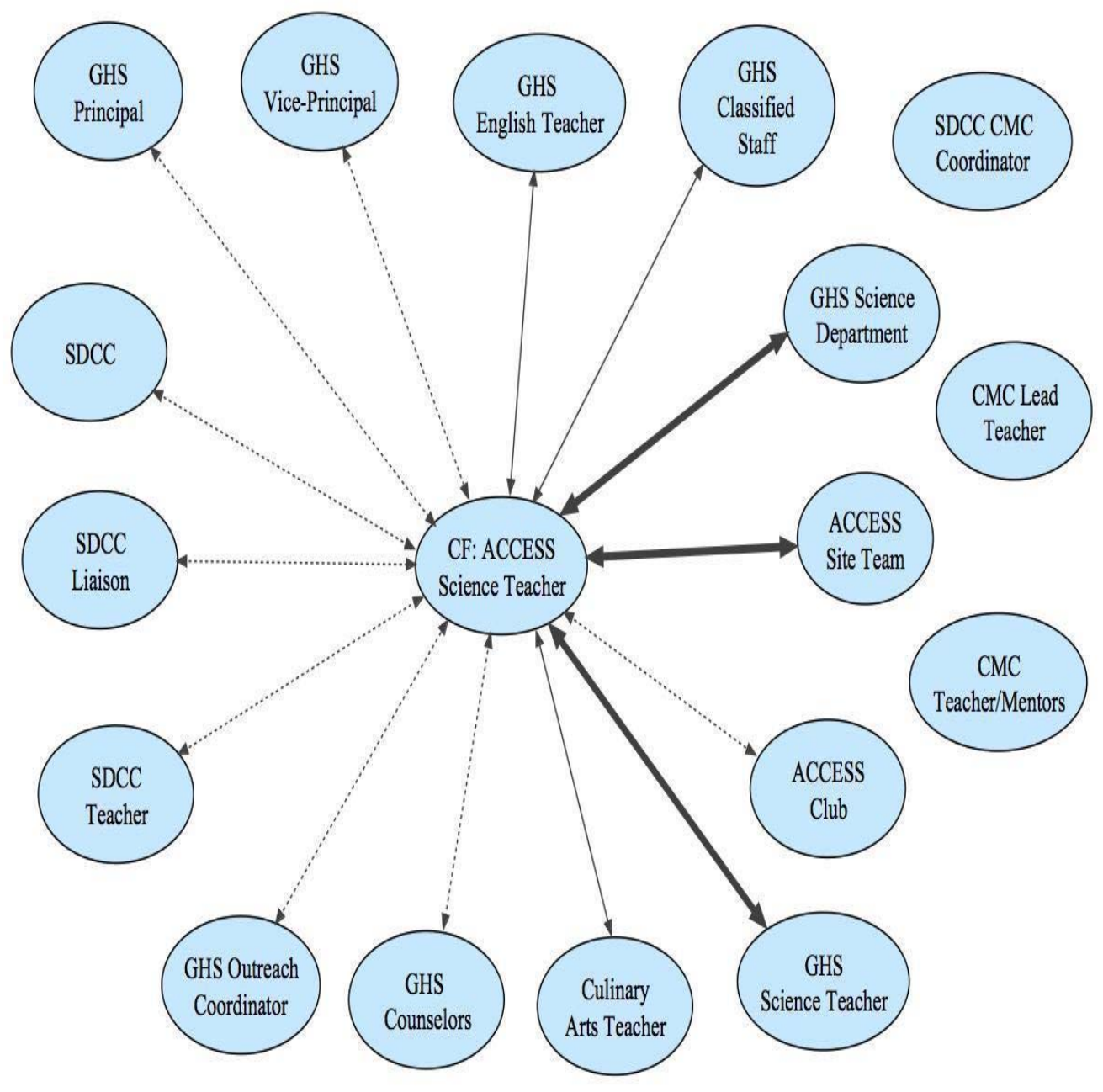

Figure 6: A diagram of $\mathrm{CF}^{\prime}$ s network structure

In order to create composites we used a numeric scale from zero to three to designate the strength of a connection. A zero meant no connection and a three meant a strong connection. Then, based on the diagrams we had constructed for each respondent, we assigned numerical values to each respondent's connections. We arrived at an average strength of a specific connection by summing 
DAVID WHITE AND JAMES LEVIN

the numerical values for a particular connection within each group then dividing by the number of individuals in that group. Figure 7 shows the composite network structure for ACCESS teachers.

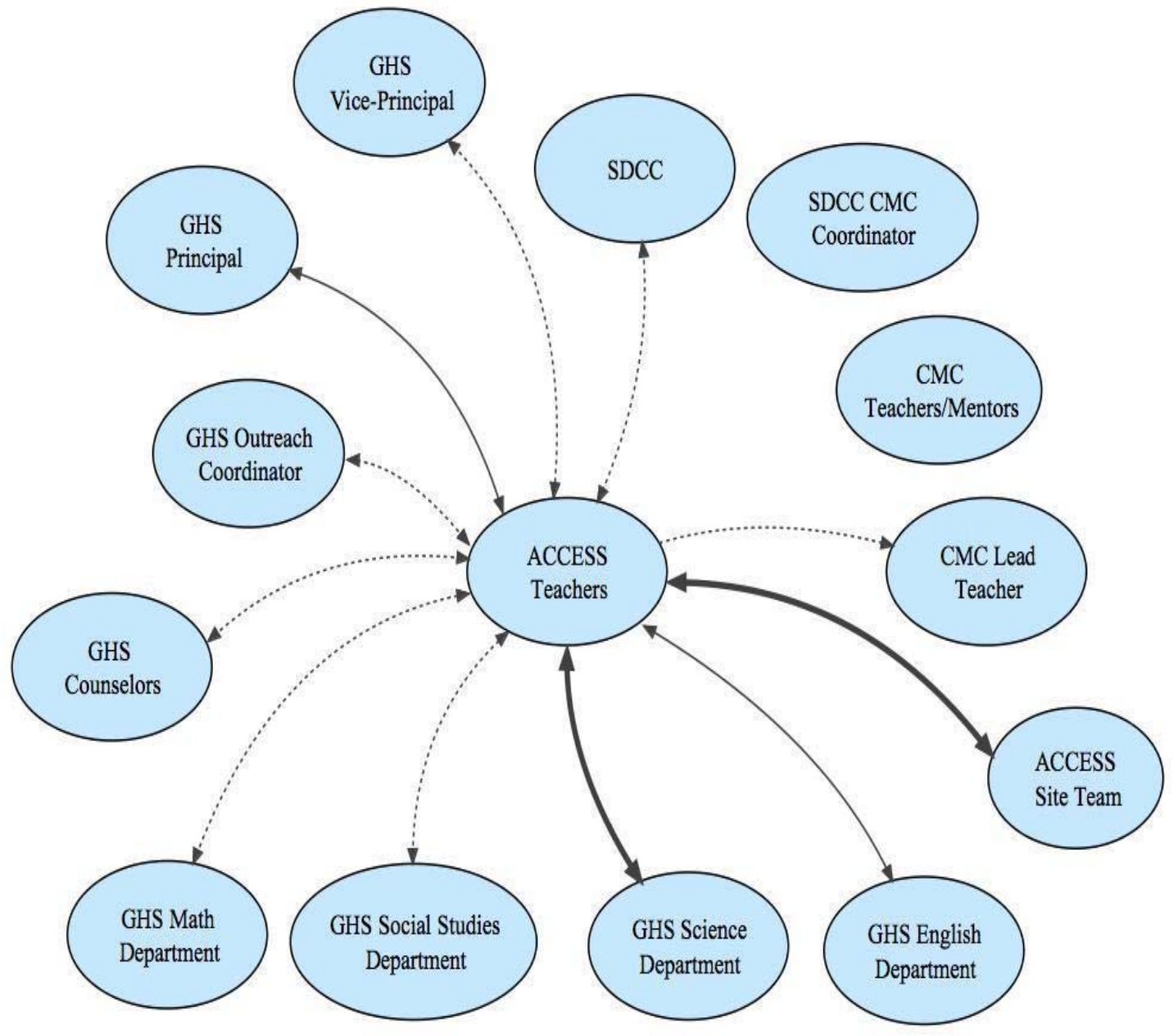

Figure 7: A composite of network structures for ACCESS teachers

Based on network structure diagrams constructed from audio-recorded interviews and from GHS documents detailing standard operation procedures for enrolling GHS students in SDCC courses, the first author constructed a network structure diagram for enrolling GHS students in SDCC courses (Figure 8). 


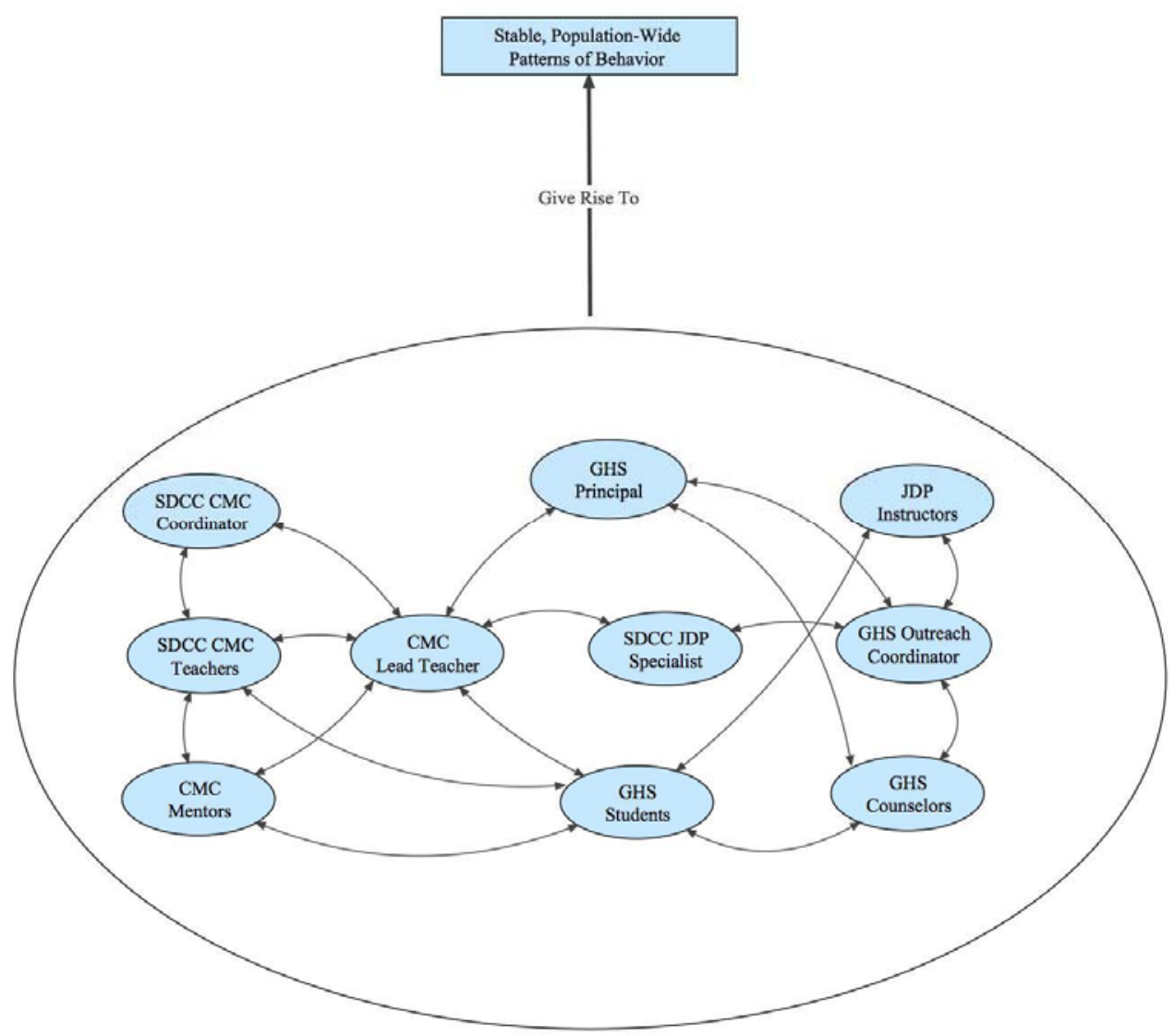

Figure 8: The network structure of GHS-SDCC.

The network structure diagram illustrated in Figure 8 shows:

- There were two programs for enrolling GHS students in SDCC course, the JDP and CMC.

- GHS students were connected to non degree-track JDP courses at SDCC such as personal growth and business math through their counselors and the GHS outreach coordinator, and to CMC through their counselors and the CMC lead teacher. GHS students were also connected to CMC and JDP instructors through the classes they were taking at SDCC.

- Other than the GHS teachers who were also teaching at SDCC, GHS teachers had no direct connection to anyone at SDCC and were not part of the network structure for determining which college classes that GHS students enrolled in at SDCC.

The network structure in Figure 8 is informative not only for what it shows, but for what is not there.

- There were no network structure connections between GHS and the various academic departments at SDCC. The existing network structure did not include connections that would allow GHS students to enroll in degree-track college classes.

- The ACCESS site team was not part of the network structure for enrolling GHS students in SDCC courses. 
Creating a New GHS-SDCC Network Structure:

DAVID WHITE AND JAMES LEVIN

In order to enroll students in the degree-track courses that had been targeted by the ACCESS site team, it was necessary to create a new network structure (Figure 9).

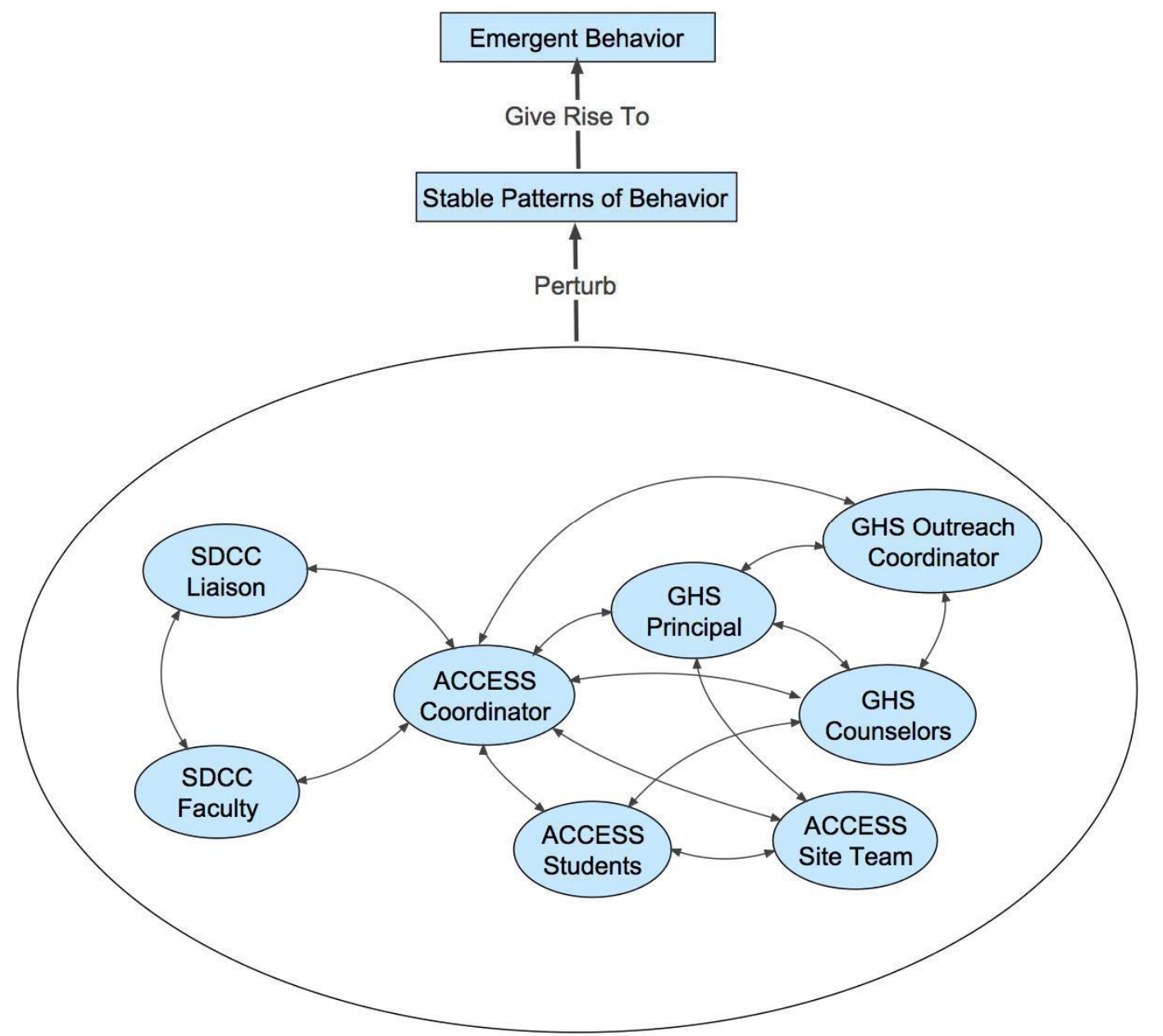

Figure 9: A new network structure for enrolling ACCESS students in SDCC degree-track courses.

As the ACCESS coordinator, the first author developed a network structure with various academic departments at SDCC and acted as a "bridge" for enrolling GHS students in degreetrack courses at SDCC. Once an ACCESS student was guaranteed admission to a degree-track course at SDCC and had the approval of their high school guidance counselor, enrolling the ACCESS student in that course followed the same standard operating procedures as those for enrolling GHS students in JDP courses (shown in Figure 8).

However, the new network structure did not replace the existing network structure. GHS counselors were still recommending which SDCC courses their students should take and prior to the existence of the new network structure, a GHS student would chose to enroll in a specific SDCC course based solely on the recommendations of her/his high school counselor. What had changed was that ACCESS teachers were recommending specific SDCC courses to their ACCESS students and the first author was coordinating efforts to get students enrolled in those courses. 


\section{Competing Network Structures:}

GHS counselors continued to recommend JDP courses and CMC to their students where ACCESS teachers were recommending selected degree-track courses. One example where this happened was with SJ, an African-American student, who had been an ACCESS student for two years. Based on the advice of her ACCESS teachers, she completed one semester of transfer-level courses at City College in Science, Math, and English during her senior year in high school. In an interview, SJ credits the ACCESS teachers, not her counselor, with providing her with support for college preparation.

DW: How much counseling did he [SJ's counselor] do for your college prep here? In other words, the courses you took, sort of advising on what you should take and things like that?

SJ: He wasn't much involved in that at all. I kind of had my own little plan of what I wanted to do, wanted to get done, based on what I really wanted to do but I wanted to get all my General Ed done and he wanted me to take like Personal Growth or something. I mean, it was an OK class but I just wanted to focus on my General Ed so I could go forward.

DW: You said earlier that you got some sort of direction from some of the ACCESS Teachers? SJ: Yes.

DW: Did most of that academic discussion come in that area [with the ACCESS teachers] rather than your counselor?

SJ: Yeah it did. They [ACCESS teachers] helped me focus where I really wanted to focus my energy and studying and the classes I wanted to take more than he did.

SJ's responses illustrated a common problem. ACCESS teacher and GHS counselors frequently recommended different college courses for the same student. This environment of competing network structures created perturbations that impacted the existing patterns of behavior for enrolling GHS students in classes at SDCC. ACCESS students were receiving conflicting advice about which college courses they should take and in the process, emerging tensions between ACCESS teachers and GHS counselors escalated. As one counselor said, "The problem is my students now have two counselors."

This environment of escalating tension was evident in an interview the first author conducted with BG, GHS's head guidance counselor in June of 2009. BG felt that ACCESS teachers were counseling students without a counseling credential and we were jeopardizing our jobs, and the school.

BG: And if the ACCESS team, of which there's no one with a counseling credential, is advising students, I think it's against Ed code. I've mentioned this to the principal. That I question what would happen if a family they came in and came back and said: You told my student that? Where did you get the idea that you had the right to advise my students? I've been in schools where they [teachers] were not allowed to have meetings with students unless there was a counselor there. That they couldn't have an ACCESS or an AVID meeting discussing college careers without someone there who really had a credential and the knowledge.

Despite the first author's efforts to act as a bridge between GHS and SDFCC, BG felt that the counselors were not aware of what was going on.

BG: But there is not very much communication. The counselors don't know which students are going to be taking which college courses. And when I share this information with other people, they're stunned. 
The Role of the School's Principal

From the beginning, the Principal of GHS adopted a hands-off approach, letting the teachers involved in ACCESS develop the program. When ACCESS teachers met with resistance from other staff members, primarily the Counseling Department and the Vice-Principal, the Principal's main role was to act as a buffer from criticism directed at ACCESS and the teachers involved with ACCESS, and to clear away attempts to block the development of ACCESS. So while, within GHS, change was being initiated bottom-up by teachers, the GHS Principal protected ACCESS from above, and provided the program with the opportunity to grow (White, 2011).

The Next Purposeful Perturbation: Increasing the Number of GHS Students Enrolled in ACCESS

During the five-year period from when college prep courses were first offered at GHS through the March of 2011, there was a steady increase in the number of students enrolled in college prep classes (Figure 10). From a total of 15 students enrolled in AVID classes in the spring of 2007, the college prep program grew to a peak enrollment of 74 students enrolled in ACCESS classes during the 2010-2011 school year, or about 20 percent of GHS's student population.

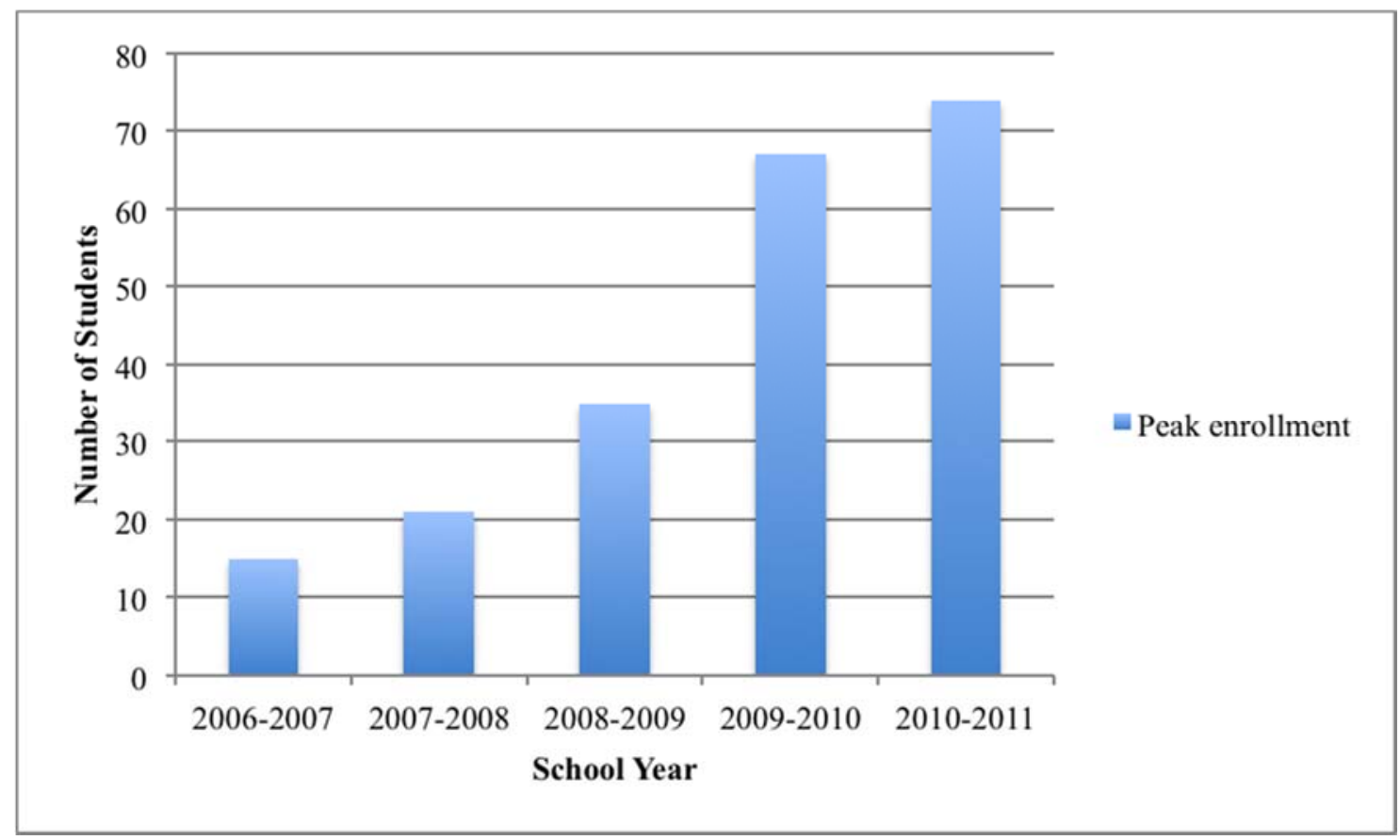

Figure 10: ACCESS enrollment 2006-2011

One reason enrollment numbers had increased is that more college prep courses were added to GHS's course options. In the spring of 2007 GHS offered only two ACCESS Classes college prep classes, one in English and one in math. By the 2010-2011 school year there were eight ACCESS classes in four subject matter disciplines.

Adding additional ACCESS course offerings not only provided the opportunity for more students to participate in ACCESS, it also increased the number of teachers who were teaching 
ACCESS classes. The number increased from two ACCESS teachers in 2007, to seven ACCESS teachers by the 2010-2011 school year, or 25 percent of GHS's teaching staff.

There were other reasons for enrollment growth. GHS students knew about ACCESS and understood that it was about preparing for college. According to DA, who taught an ACCESS biology class:

DA: And then there's the kids, the other population, the rest of the kids know about it and that whole social dynamic, like, "Oh you're in ACCESS, so you must be wanting to go to college."

Students were enrolling in ACCESS classes because it would help them do better in school. MS, a history teacher at GHS who did not teach an ACCESS class, explained the increase in enrollment as follows:

MS: Students wanted to join ACCESS because they knew it could help them excel in school.

\section{A Tipping Point and The Expansion to School-Wide Change}

As a result of the creation of ACCESS and the strategy to use ACCESS to disrupt the equilibrium of GHS by introducing purposeful perturbations, tensions were created within the school, primarily between ACCESS teachers and GHS counselors, tensions that increased over time. By the summer of 2009, those tensions had reached a critical point.

On June 18th 2009, the GHS counseling staff was having a meeting at GHS in an open area adjacent to the counseling offices. The counselors were sitting around a large round table and the first author could hear them discussing ACCESS. He had some materials to give the counselors, so he walked over to their table and asked if he could give them an updated list of students that the ACCESS site team was recommending for the ACCESS program for the next school year.

At that point, BG, the head counselor, told him, "We just want you to know that we are discussing whether we are going to vote to file a grievance with the district against you and your fellow ACCESS teachers." The first author asked him why. He said, "Because you are counseling students, you don't have a credential, and we are considering filing a grievance with the district against the ACCESS teachers." BG added that the counselors were meeting with the principal in two hours to discuss their decision. The first author asked if he wanted him at the meeting with the principal and he said, "I really don't care whether you are there or not."

The first author sat down at the table and the counselors began to tell him why they were considering filing a grievance. They felt that the ACCESS teachers had stepped in and were contradicting them, that the ACCESS teachers did not have counseling credentials, and that were putting the school at risk. They said that they could not tolerate that anymore. The first author told them that he was no longer willing to put up with the existing situation either. He added that if they could not come to some kind of agreement, he was not going to be part of the ACCESS program anymore. He then asked them if they had any suggestions.

$\mathrm{AV}$, one of the counselors, said: "ACCESS is becoming the largest program in the school. We think that what the ACCESS teachers are doing is great for our students but we have their best interests at heart too." At that point BG suggested that what we needed to do was set up a time when the counselors and the ACCESS team could meet on a regular basis to try and work things out. The first author told them he thought that this was a good idea. BG said that the counselors would like to come up with a list of suggestions before they met with the school principal. The 
DAVID WHITE AND JAMES LEVIN

first author told them that he would return when they met with the principal and left the meeting. The last thing that he said was: "Just tell us what you want".

\section{The Creation of a New ACCESS Site Team}

About an hour later, the counselors and the first author met with the principal and the discussion was very positive. The GHS counselors presented the following list of suggestions at that meeting:

- Set up a day and time for ACCESS teachers and counselors to meet. The following GHS staff members would attend the meetings: The GHS principal, at least one GHS counselor, the GHS outreach coordinator and the ACCESS teachers.

- All students would be informed of the number of credits required for both the 44-credit diploma and the 24-credit option 2 diploma.

- Procedures should be formalized for entrance into the ACCESS program and exiting the ACCESS program.

- The GHS counseling staff would provide ACCESS teachers with important deadlines.

It was agreed upon that our first meeting would be in September of 2009. The first item on our agenda would be to discuss the list of suggestions submitted by the counseling staff at that June meeting.

At that June 18th meeting, a tipping point was reached. Over a period of about ninety minutes, the atmosphere of the meeting changed from the counselors considering filing a grievance against the ACCESS teachers to "we need to work together". Furthermore, by agreeing to work together, this created a tipping-point moment, which is a powerful example of change that emerged out of the local interactions rather than change mandated top-down. It is not possible to get more local than a group of people sitting around a table discussing their differences.

As we stated earlier, in order for change to occur in complex adaptive systems (CAS) that are in a stable equilibrium state, it is necessary to push the systems far from equilibrium. Change occurs at critical points, bifurcation points in the language of complexity science. Consider a pile of sand: Adding sand to the pile will build it up. But at some critical point, it will collapse. Change occurs at the point where the pile of sand is just about to collapse and change happens through a process of self-organization or self-reorganization. Self-organization means that change emerges through a process of local interactions, that is, in interactions between individuals or groups of individuals that are locally connected rather than by some sort of top-down strategy or blueprint for change.

As ACCESS evolved, it pushed GHS further and further away from equilibrium. Over time, tensions between ACCESS teachers and GHS counselors reached a critical point. At that critical point, self-organization occurred through local interactions between the GHS counseling staff, the ACCESS coordinator, and the GHS principal.

During the 2009-2010 school year, the weekly ACCESS site team meetings began on September 22, 2009 and went through May 2010. The principal, ACCESS teachers and GHS outreach coordinator attended these meetings on a regular basis. The head counselor usually represented the counseling staff at those meetings. While these meeting were initially concerned 
with the ACCESS Program, over time they evolved into a discussion of a need for school-wide change.

\section{A multi-mediator model of the tension between ACCESS and the status quo}

We constructed a second model using the same multi-mediator framework as the model described previously for the shift in expectations about student capabilities for academic work. In this second model, the focus is on the interaction between the status quo at GHS (the CMC/JDP programs) and the innovation (ACCESS), as impacted by the improvement in student academic performance (an element of the first model) and the role of the principal in protecting ACCESS. This second model is shown in Figure 11.

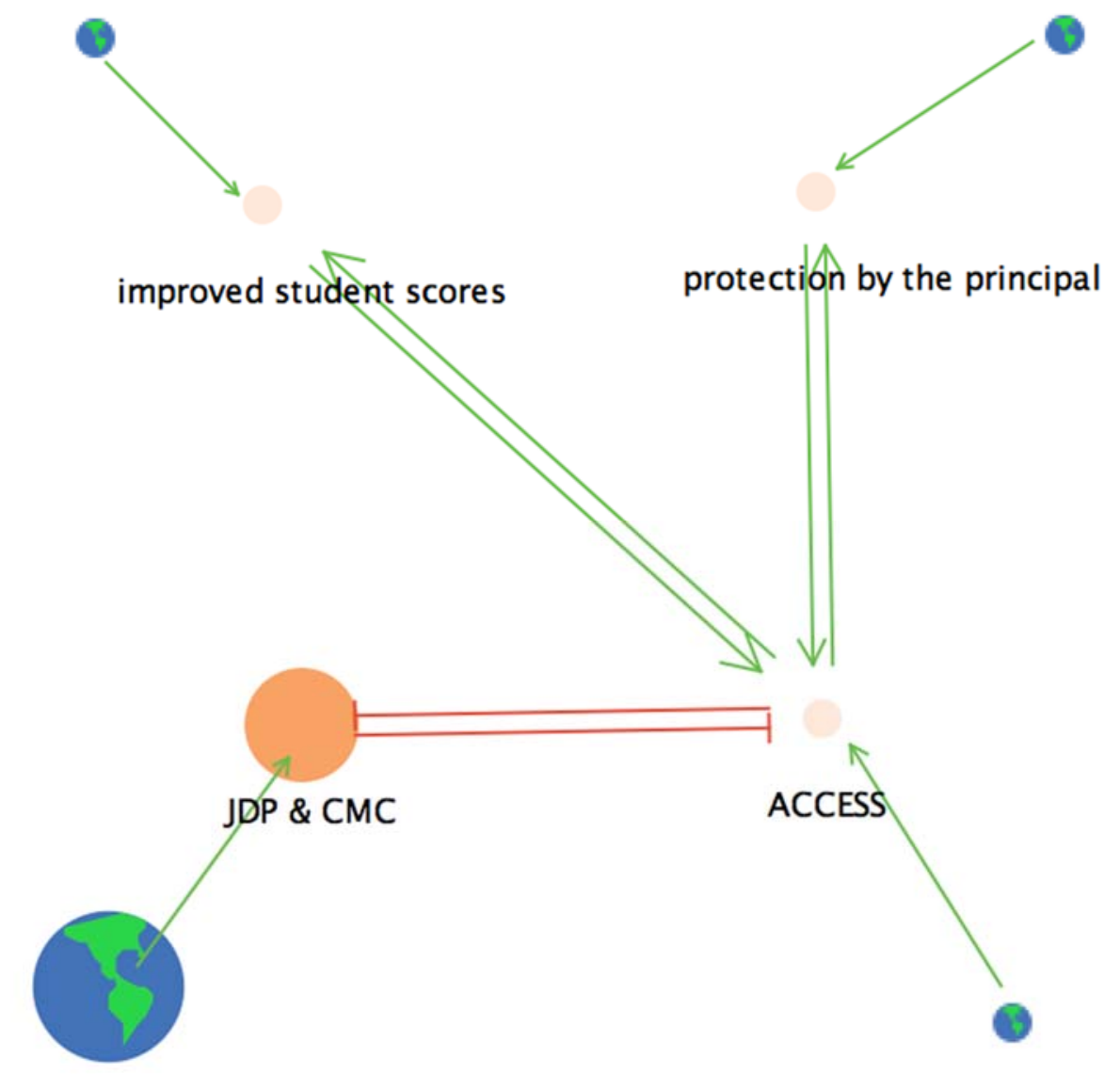

Figure 11: A multi-mediator model of the ACCESS reform tipping point, available online at https:/drive.google.com/file/d/0B24EChPrG7E REo0eGM2UWotTWs/view?usp=sharing

This model shows the joint role that the improvement of student scores on college placement exams and protection of the reform by the principal played in the non-linear change from domination of the status quo (labeled "JDP \& CMC") and the new reform ("ACCESS"). Once the tipping point is reached, the changed state of the model persists even when the context returns to its previous state. This kind of "persistent change" is a key element of successful reform, and of learning more generally. 
This model, while it captures the non-linearity of the tipping point reached on June 18th between those supporting the ACCESS program and those supporting the status quo at GHS (represented by the JDP and CMC program), it leaves out some important details. Figure 12 shows an elaborated model that captures some of these important details.

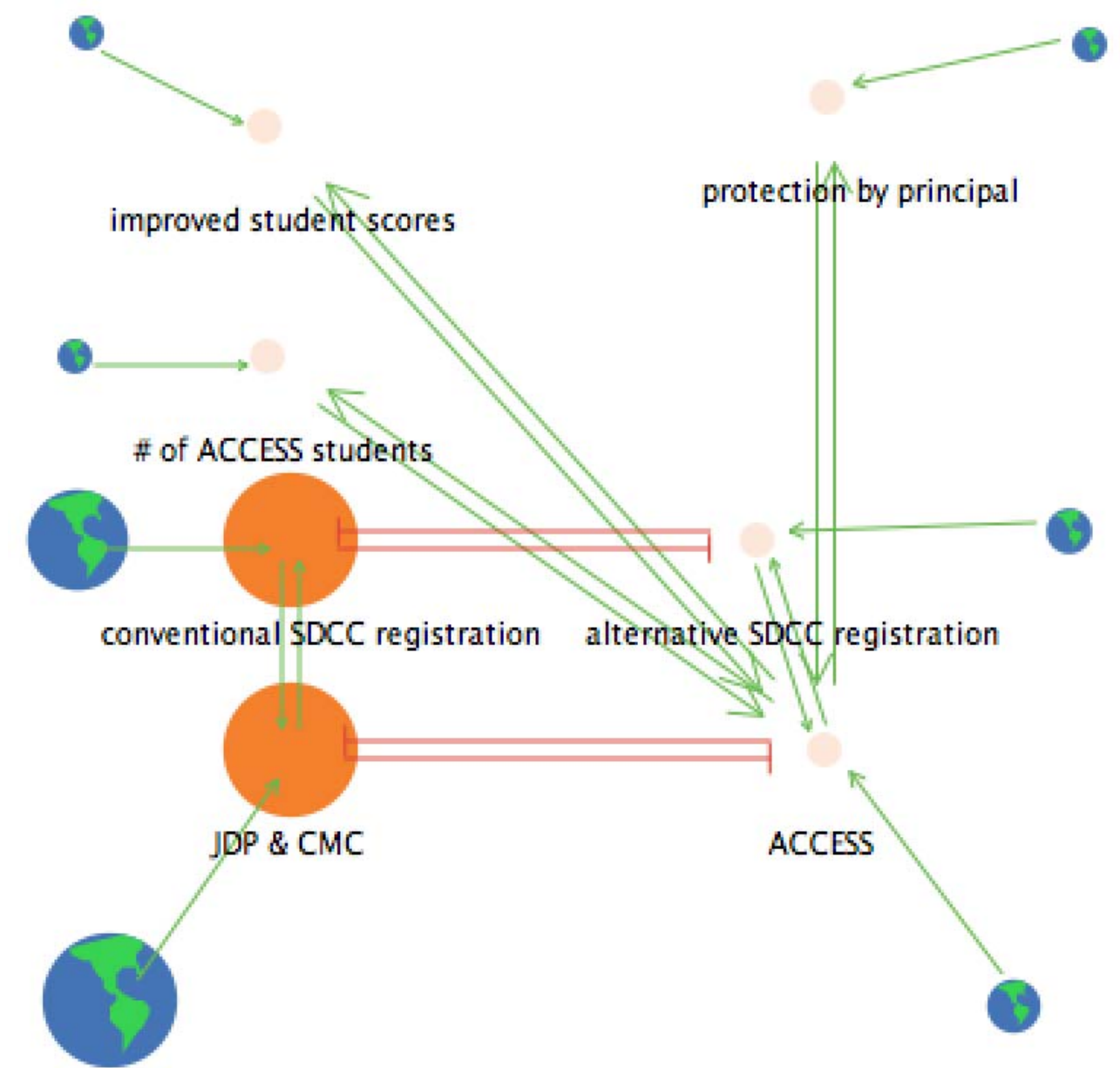

Figure 12: An elaborated multi-mediator model of the ACCESS reform tipping point, available online at https://drive.google.com/file/d/0B24EChPrG7E aWxqX3hsWEZqN2M/view?usp=sharing

The College Planning Group: The Transition to a Co-Constructing Network Structure for School-wide Change

While the development of ACCESS and meetings of the ACCESS site team had resulted in changes to ACCESS, JP, the GHS principal, and the first author believed that for change to be truly systemic, any changes in patterns of behavior needed to be institutionalized. In addition, that change needed to go beyond ACCESS. As a result, the College Planning Group (CPG) was created in October of 2010. 


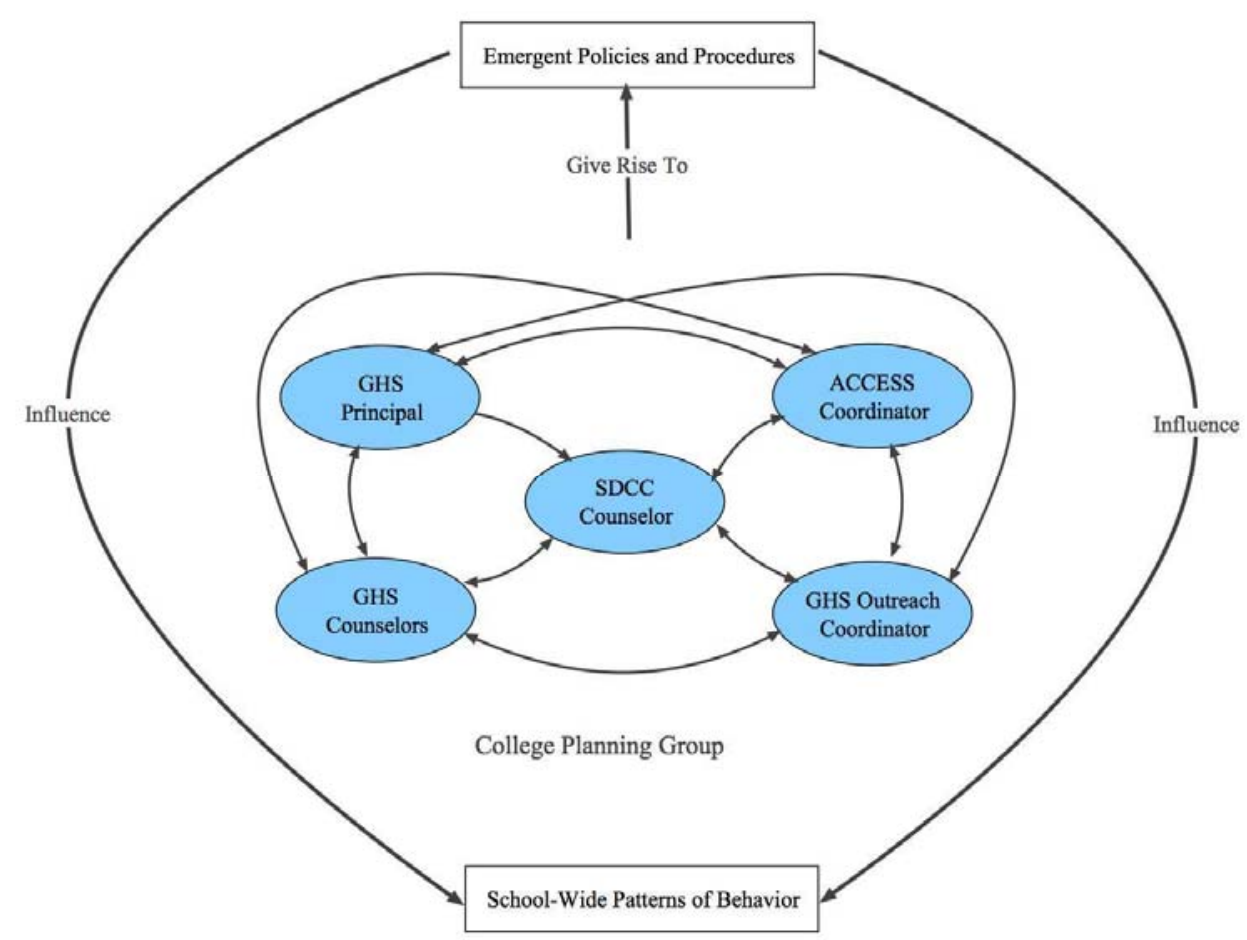

Figure 13: College Planning Group network structure

Figure 13 is a representation of the network structure for the CPG and its intended impact on GHS. While the ACCESS site team continued to be concerned primarily with policies and procedures for ACCESS, the CPG was created to develop policies and procedures for the whole school, including ACCESS. The objectives of the CPG were:

- To identify and develop GHS's processes and procedures of academic and social/emotional development and support for college prep and college coursework.

- To add to GHS's master calendar the "who, what, when and where" of the identified processes, procedures and events relate to GHS's college prep and college coursework.

- To develop an assembled college-going set of procedures for the GHS staff.

While there were many changes that emerged at GHS, one of the more dramatic changes that occurred, beginning with the 2009-2010 school year, was a major shift in the type of diploma that GHS students were earning (Figure 14). While four out of every five GHS graduates earned the 24-credit, option 2 diploma in the 2008-2009 school year, by the 2010-2011 school year, three out of every four GHS graduates earned the 44-credit diploma.

Figure 15 represents the degree of disruption existing at GHS during our design experiment, beginning with the stable state that existed February of 2007 through March of 2011, when the school was in a state of co-construction. Increasing disruption during the perturbation state was accompanied by increasing tensions, which peaked when the tipping point was reached. However, even though tensions decreased through the transition state, some degree of disruption existed since the school was still in a state of change during the co-construction state. 


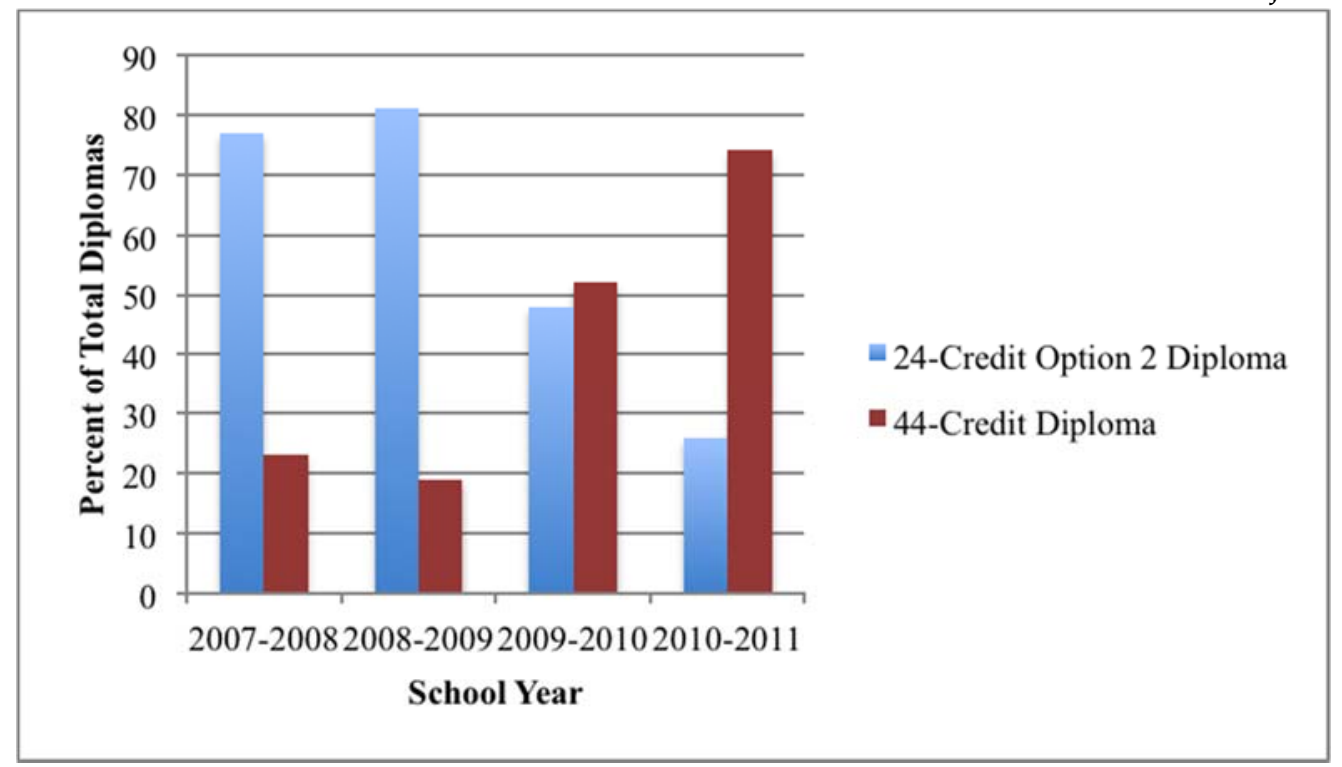

Figure 14: Option 2 diploma versus 44-credit diploma for GHS graduating seniors
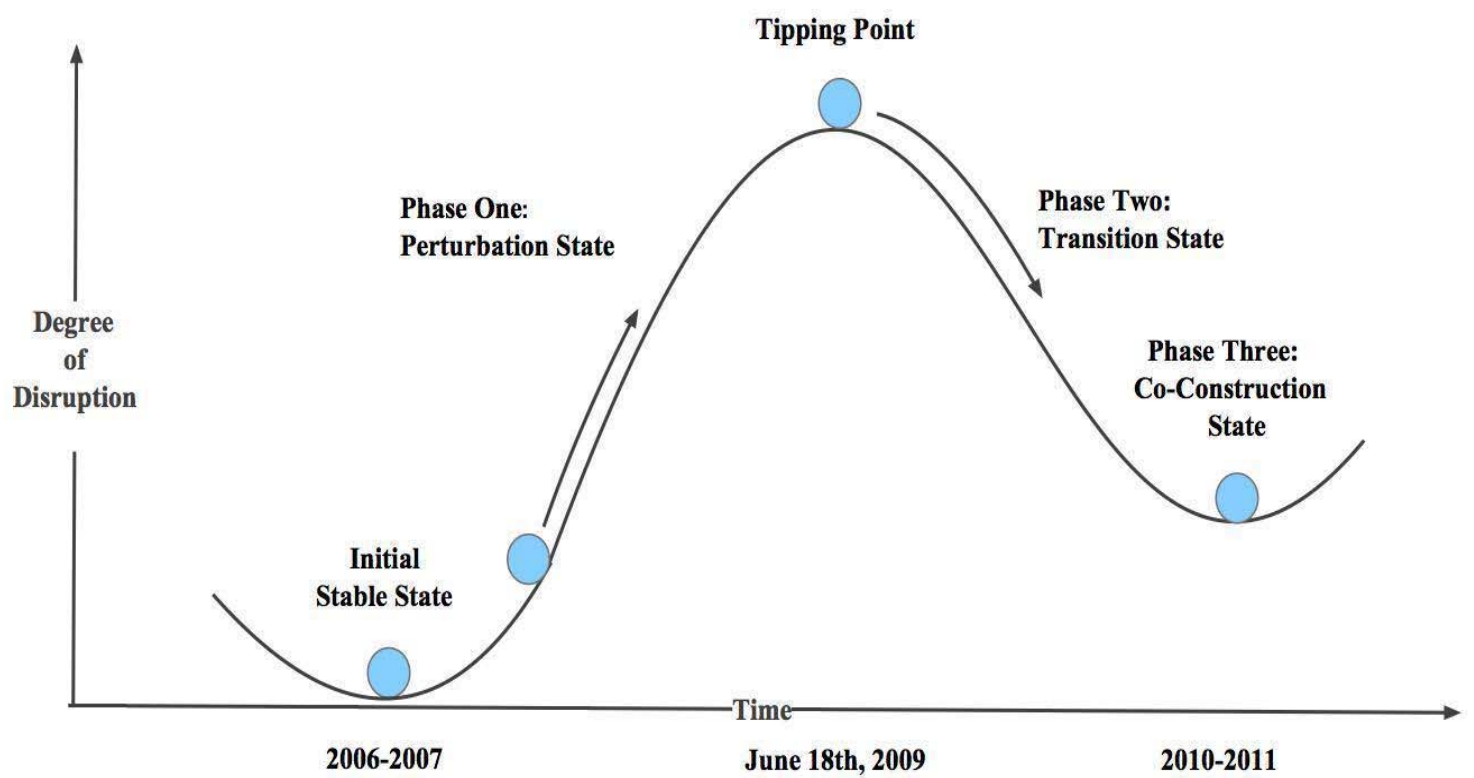

Figure 15: The evolution of GHS's organizational structure

\section{A multi-mediator model of both tipping points}

As we noted earlier, there is a common concept in each of the two multi-mediator models we presented previously. This means that we can combine the two models, to create a more complete model of the ACCESS reform process. This model is shown in Figure 16. 


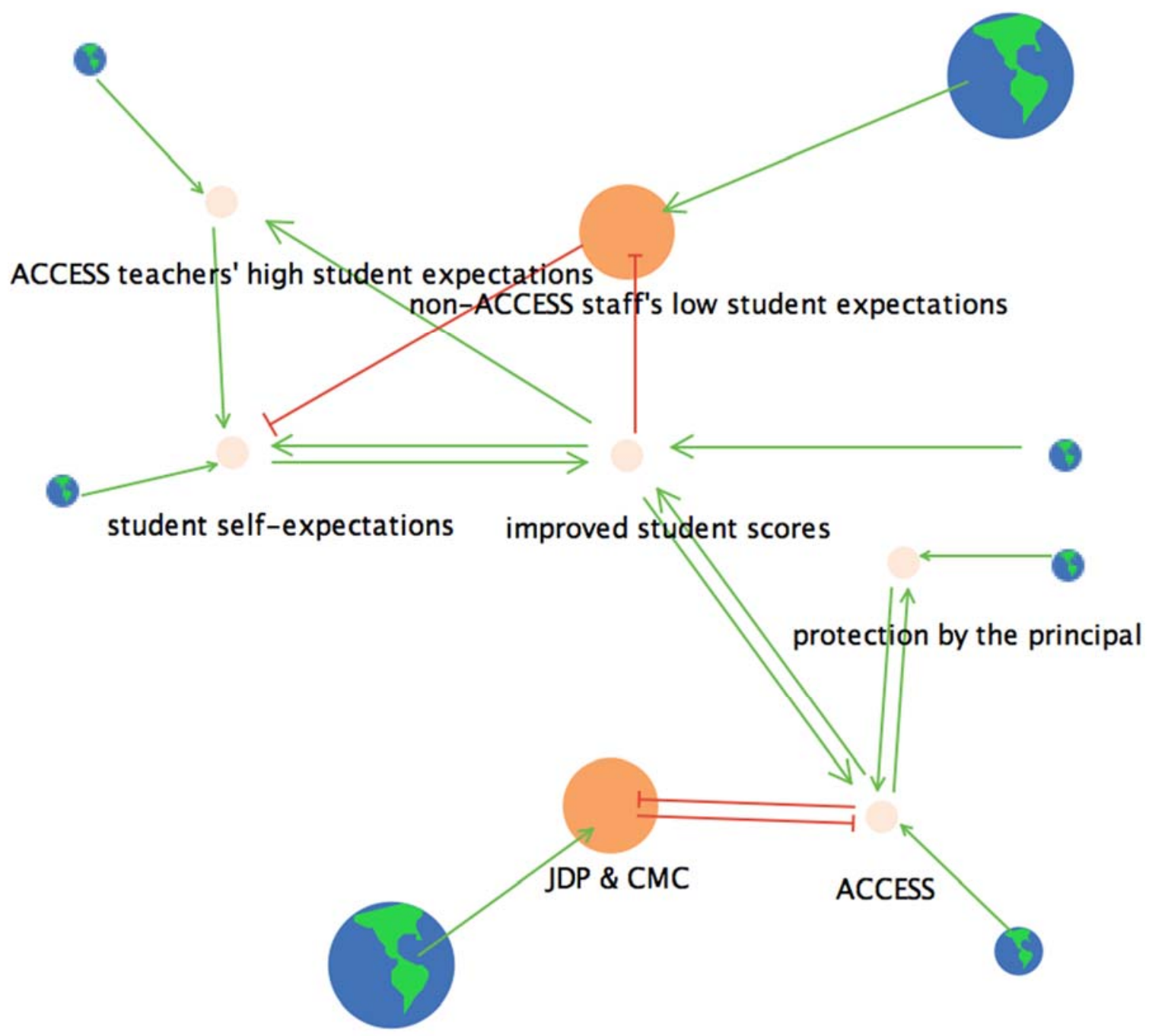

Figure 16: A combined multi-mediator model of the ACCESS reform, available online at https://drive.google.com/file/d/0B24EChPrG7E_MnhWRV9KNmJDYk0/view?usp=sharing. The model contains two tipping points, which can either cascade into one overall non-linear change or can exhibit two separate non-linear changes over time, depending on the sequence of changes in context.

\section{Impact of the reform beyond the school}

Since 1996, when the JDP program was first introduced, it had been the practice of high school counselors throughout the St. Diaz Unified School District (SDUSD) to inform many of their students who were transferring to GHS that they were recommending them for the 24-credit, option 2 diploma program. The option 2 diploma was designed for older students (seventeen and a half to eighteen years old) who were severely credit deficient. However, in many cases, the students sent to GHS did not meet the requirements for option 2.

Given the changes that had taken place at GHS, this practice became problematic. As evidenced by the type of diploma students earned for the 2009-2010 school year compared with 
DAVID WHITE AND JAMES LEVIN

the type of diploma students had earned in previous years (shown in Figure 14), GHS was moving toward a 44-credit school. For the 2010-2011 school year many of the students sent to GHS who were expecting to pursue the option 2 diploma were being told by their GHS counselor that they would need to pursue the 44-credit diploma. This resulted in negative reactions by many of those students who were resistant and surprised that they would have to pursue the regular 44-credit diploma.

Because guidance counselors from other SDUSD high schools were recommending the 24credit option 2 diploma to their students who were transferring to GHS, many of whom did not meet the criteria for that diploma, at the request of the GHS principal, an email was sent to all SDUSD counselors by the GHS counselor responsible for student intake on January 10, 2011 informing them that GHS had shifted its academic expectations (shown in the email in Figure 17). Students referred to GHS were expected to pursue a 44-credit diploma. The changes that had occurred at GHS, due in large part to the impact of ACCESS, were beginning to have an impact on other schools in the district. The impact had moved beyond GHS.

During the past three school years, there has been a spike in student interest and demand for the ACCESS program, and most ACCESS classes are now filled to capacity. Building collegereadiness capacity is explicitly discussed every day in class. In ACCESS English and social studies, coursework is designed to meet students at their current skill level and provide support as they tackle college level texts and writing assignments involving rigorous discussion and analysis. ACCESS math pushes students to prepare to test into college level math upon graduation. The typical Garfield student arrives with 6-7th grade level math skills. Since ACCESS started, 55\% of Garfield's ACCESS students who took the math placement exam tested into college-level math and $90 \%$ tested into at least associate level college coursework, with the numbers increasing each year. In comparison, only about $66 \%$ of adult students applying to the community college test into college level math, with only $4 \%$ testing into a transfer level math course.

\section{Summary}

Prior to the creation of an innovative college prep program, Academic Commitment Creates Empowered Successful Students (ACCESS), virtually all GHS graduates lacked the academic skills necessary for success in rigorous college coursework, as evidenced by their placement on College Math and English assessment exams. GHS graduates who took college assessment tests placed into the lowest levels of remedial math and English.

From 2007, the first year of this educational reform, through 2010, ACCESS achieved increasing success in preparing low-income, low-performing underrepresented minority students for rigorous college coursework. These results, documented in this research study, have implications for low-performing students at high schools more generally.

There are students like those at GHS throughout the SDUSD. In fact, there are high school students like those at GHS throughout the United States and around the world. In the SDUSD there are 22 traditional high schools, with a total enrollment of over 30,000 students. The 2009 Standardized Testing Annual report (STAR) showed that of the 4724 SDUSD high school students 


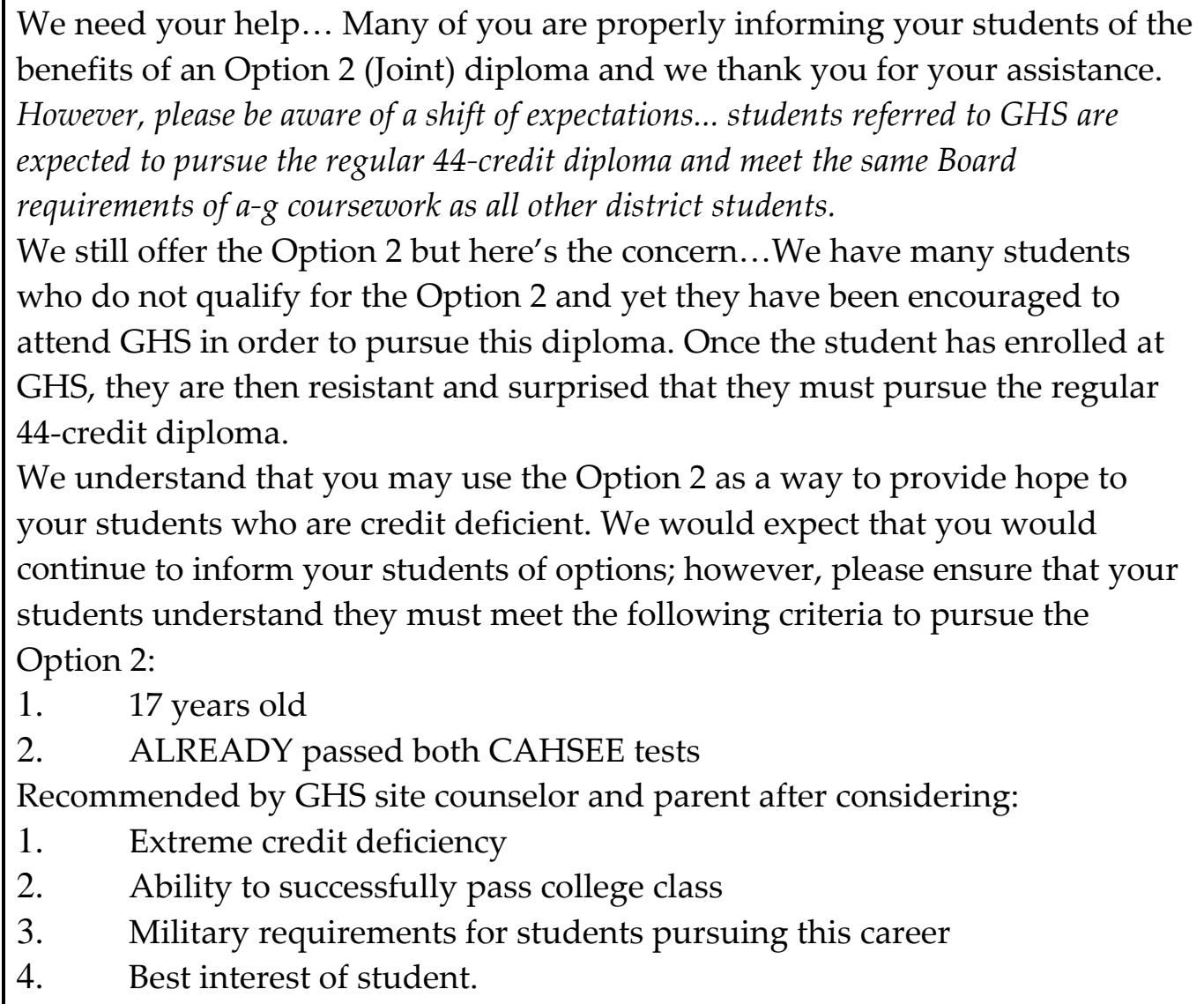

Figure 17: E-Mail sent to all SDUSD counselors by GHS's intake counselor

who took the 2009 CST in Algebra I, 2173 (46\%) students scored "below basic". Of those 4724 students, 1249 (26\%) scored "far below basic".

Some of those low performing SDUSD high school students transfer to GHS, but most remain at their home school. In general, low-performing high school students are tracked into low-ability classes designated for those students deemed non-college bound (Oakes \& Guiton, 1995) where there is little opportunity to prepare for college. College prep programs tend to be for high performing students. Even Advancement Via Individual Determination (AVID), a college prep program initially designed for low-performing students has evolved into a college prep program for students "in the middle", and so is not for low-performing students. Furthermore, college prep programs tend to be designed for academic preparation for four-year colleges and universities, rather than for community colleges.

Our research shows that while not all high school graduates will be prepared for college, students who have a history of little success in school should not be put on a fast track to a high school diploma that does not lead to further education. All students should be provided with the opportunity to take high school classes that prepare them for college and provide them with the necessary support for success in those courses. 


\section{Complexity Theory As a Strategy For School Reform}

The focus and purpose of this research study was to promote educational change through a design experiment. Treating an innovative college prep program, ACCESS, as a nested Complex Adaptive System (CAS) within a larger CAS, Gonzago High School (GHS), we used features of complexity theory as a framework to design a strategy for school reform. The model for school reform that evolved, which showed documented success, has implications for how schools can achieve transformational change.

A strategy we call "purposeful perturbations" was used to push GHS away from its equilibrium state. The result was that a critical point, what is referred to in complexity theory as a bifurcation point, was reached where a textbook example of self-organization occurred when GHS counselors and ACCESS teacher agreed to work together.

Purposeful perturbations can be an effective strategy for accomplishing the goal of educational reform. However, based on our research, we make some recommendations about the nature of those perturbations.

Each perturbation must have a purpose other than just creating instability. The perturbations introduced at GHS had a dual purpose. The espoused mission of ACCESS was to prepare students for post-secondary education, primarily college. Raising the level of students' academic performance and creating a network structure with SDCC for enrolling ACCESS students in degree-track college courses were consistent with that mission. A second purpose was to create conditions for school-wide change.

If you push people, people will push back. Perturbations designed to push a school away from equilibrium will encounter resistance. Perturbations must be designed with the purpose of breaking down that resistance. The perturbations that pushed GHS away from equilibrium created increasing tensions, primarily between ACCESS teachers and GHS counselors. However, increased levels of academic performance by ACCESS students and the success of ACCESS students in degree-track college courses provided disconfirming evidence that challenged the low academic expectations of GHS counselors and, over time, broke down their resistance.

\section{Change Can Begin in the Classroom}

According to complexity theory, patterns of behavior that emerge in localized parts of a CAS can bubble up, resulting in changes in patterns of behavior throughout the system. In our design experiment, the patterns of behavior that emerged as ACCESS evolved resulted in school-wide changes. The results of our design experiment have implications for school reform efforts in general.

Many school reform efforts are top-down, hierarchical affairs, with students at the bottom of the hierarchy being passive receptors of the reform. The reform model in this study started with the teachers, but in raising students' levels of academic performance on college assessment exams and successfully completing academically rigorous college classes, students became agents of change rather than passive recipients. So change that begins in the classroom can be an effective approach to school reform. 


\section{The Role of Emergence}

In complex adaptive systems, there is no master controller or prescribed blueprint for change (Stacey, 2007). Instead, local interactions between agents, operating according to their own rules, result in a process of self-organization, giving rise to emergent, often unpredictable, new structures and new patterns of behavior. The less than predictable nature of complex systems means that practitioners have less control over outcomes. In this sense, school reform is more an opportunistic form of activity than a planned form of activity. Radford (2007) states that "In this context the practitioner is less like the bulldozer driver carving a way through the landscape to a pre-conceived objective, more like a combination of a canoeist shooting the rapids and creative artist exploring possibilities and waiting for inspiration" (p. 275).

For example, when GHS counselors continued to recommend non-degree-track college courses for ACCESS students who had tested into transfer-level college courses on college assessment tests, the first author determined that the existing network structure between GHS and SDCC was not adequate for enrolling GHS students in degree-track college courses. His response was to create a new network structure with SDCC.

\section{Implications for the Research-Practitioner}

From Labaree's (2003) point of view, researchers in education investigate important issues by doing research but it is up to practitioners to put their research findings into practice. In contrast, the design experiment approach to doing research stresses the value of building theory and improving practice at the same time (Brown, Greeno, Resnick, Mehan, \& Lampert, 1999). One way to do this is by researchers and practitioners working together to develop and test theories in real-life situations. Another way is for research-practitioners to conduct design experiments where the research practitioner acts as the researcher, developing theories, and the practitioner tests those theories in real-life situations.

In our research we constructed a design experiment to develop and test a theory of school reform in a real-life context, a continuation high school for low-income, low-performing underrepresented minority students. The first author acted as researcher, by developing theory, and practitioner, by testing that theory. The implications for research practitioners is that their research can go beyond describing what works and what doesn't work and then passing their findings and recommendations on to practitioners. They are practitioners themselves. The job description of the research-practitioner should include fixing problems in education. Ultimately, the goal of educational research is lasting educational improvement.

Since this study ended, during the school years of 2011 to 2014, there has been a spike in student interest and demand for the ACCESS program, and most ACCESS classes are now filled to capacity. Building college-readiness capacity is explicitly discussed every day in class. In ACCESS English and social studies, coursework is designed to meet students at their current skill level and provide support as they tackle college level texts and writing assignments involving rigorous discussion and analysis. ACCESS math pushes students to prepare to test into college level math upon graduation. The typical Garfield student arrives with 6-7th grade level math skills. Since ACCESS started, 55\% of Garfield's ACCESS students who took the math placement exam tested into college-level math and $90 \%$ tested into at least associate level college 
DAVID WHITE AND JAMES LEVIN coursework, with the numbers increasing each year. In comparison, only about $66 \%$ of adult students applying to the community college test into college level math, with only $4 \%$ testing into a transfer level math course.

We are currently interviewing former students who participated in the ACCESS reform to see what impact it has had on them several years later. We want to discover the ways in which ACCESS provided under-performing, underrepresented students with the academic and collegegoing skills necessary for success in college, we want to know how these students experienced the transition from high school to community college and from community college to a four-year institution, and we want to better understand the factors that supported or constrained their performance in college coursework and impact persistence in pursuing a college degree to completion.

We do not think that our research provides a blueprint for an education reform that can be duplicated elsewhere - instead we hope that our research provides a guide to help others to navigate the turbulent waters of school reform, informed by complexity theory. The exact nature of "purposeful perturbations" will differ from setting to setting, but this technique for generating persistent change may apply widely. We hope that our existence proof of a successful teacherinitiated educational reform will inspire educational participants at all levels to take an active role in improving education. And we hope that our research shows that complexity theory can not only describe educational reform but can also productively guide it.

\section{References}

ACT. (2010). Mind the gaps. How college readiness narrows achievement gaps in college success. Iowa City, IA: Author.

Adelman, C. (2004). Principal indicators of student academic histories in postsecondary education, $1972-2000$. Washington, DC: U.S. Department of Education.

Allen, P. M. (2001). A complex systems approach to learning in adaptive networks. International Journal of Innovation management, 5(2), 150-180.

Anderson, P. (1999). Complexity theory and organization science. Organization Science, 10(3), 216-232.

Beabout, B. R. (2012). Turbulence, perturbance, and educational change. Complicity: An International Journal of $\begin{array}{llll}\text { Complexity and } \quad \text { Education, } & \text { Retrieved }\end{array}$ http://ejournals.library.ualberta.ca/index.php/complicity/article/view/17984 .

Brown, S., \& Eisenhardt, K. (1998). Competing on the edge. Boston, MA: Harvard Business School Press.

Brown, A., Greeno, J. G., Resnick, L. B., Mehan, H., \& Lampert, M. (1999). Recommendations regarding research priorities: An advisory report to the National Educational Research Policy and Priorities Board. New York, NY: National Academy of Education.

California Department of Education. (2013). California Education Code, 48400-48438. Available online at http://www.cde.ca.gov/sp/eo/ce/ .

Capra, F. (1997). The web of life. New York, NY: Anchor Books.

Carey, K. (2004). A matter of degrees: Improving graduation rates in four-year colleges and universities. Washington, DC: The Education Trust.

Cilliers, P. (2001). Boundaries, hierarchies, and networks in complex systems. International Journal of Innovation Management, 5(2), 135-147.

City Middle College Grant (CMC). (1999). Grant Proposal.

Cobb, P., Confrey, J., diSessa, A., Lehrer, R., \& Schauble, L. (2003). Design experiments in educational research. Educational Researcher, 32(1), 9-13. 
Collins, A. (1999). The changing infrastructure of educational research. In E. Lagemann \& L. Schulman (Eds.), Issues in educational research: Problems and possibilities (pp. 289-298). New York, NY: Jossey-Bass.

Daly, A. J. (2010). Mapping the terrain: Social network theory and educational change. In A. J. Daly (Ed.), Social network theory and educational change (pp. 1-16). Cambridge MA: Harvard Education Press.

Elmore, R., \& Burney, D. (1999). Investing in teacher learning: Staff development and instructional improvement. In L. Darling-Hammond \& G. Sykes (Eds.), Teaching as a learning profession (pp. 263-291). San Francisco: Jossey-Bass.

Fullan. M. (1999). Change force: The sequel. Philadelphia, PA: Falmer Press, Taylor \& Francis Inc.

Gell-Mann, M. (1994). The quark and the jaguar: Adventures in the simple and the complex. New York, NY: W. H. Freeman.

Halter, C., \& Levin, J. (2013). Multi-mediator models of new teacher learning through creating multimedia. Paper presented at the 2013 American Educational Research Association meetings. San Francisco, CA. Available online at http://tinyurl.com/Halter-Levin-AERA2013-paper .

Holland, J. (1998). Emergence from chaos to order. New York, NY: Oxford University Press.

Hubbard, L., Mehan, H., \& Stein, M. K. (2006). Reform as learning: School reform, organizational culture, and community politics in San Diego. New York, NY: Routledge Taylor \& Francis Group.

Hurtado, S., Inkelas, K. K., Briggs, C., \& Rhee, B-S. (1997). Differences in college access and choices among racial/ethnic groups: Identifying continuing barriers. Research in Higher Education, 38(1), 43-75.

InqScribe (2011). Version 2.1 [Computer Software]. Chicago, IL: Inquirium, LLC

Jones, M., Yonezawa, S., Ballesteros, E., \& Mehan, H. (2002). Shaping pathways to higher education. Educational Researcher, 31(2), 3-11.

Kauffman, S. (1995). At home in the universe. New York, NY: Oxford University Press.

Labaree, D. F. (2003). The peculiar problems of preparing educational researchers. Educational Researcher, 32(4), 13-22.

Langton, C. G. (1996). Artificial life. In M. A. Boden (Ed.), The philosophy of Artificial Life. Oxford: Oxford University Press.

Levin, J. (2015). Creating and evaluating multi-agent models of learning with qualitative and quantitative data. Available online

at: https://docs.google.com/document/d/15mJloMh4sZ_CGnEYjMYHLjoTc6tXhbQyE75A4Eqj1Xc/edit?pli=1\# .

Levin, J., \& Datnow, A. (2012a). Multiple mediator models of educational reform: Organizational learning as persistent change. Paper presented at the 2012 American Educational Research Association meetings. Vancouver Canada. Available online at https://docs.google.com/document/d/1vAWrhD4hpLD_JU6C5c0jSELiqfG_-1sZ4beYlNb1A/edit?pli=1 .

Levin, J., \& Datnow A. (2012b). The principal role in data driven decision making: Using case study data to develop multi-mediator models of educational reform. School Effectiveness and School Improvement, 23(2), 179-201.

Levin, J. A., Jacobson, M. J., \& Markauskaite, L. (2014). Combining computational modeling, theory, and data: Steps toward a meta-model framework for the study of learning. Paper presented at the 2014 American Educational Research Association meetings. Philadelphia, PA. Available online at: http://tinyURL.com/LJMAERA2014

Marion, R. (1999). The edge of organization: Chaos and complexity theories of formal social systems, Thousand Oaks, CA: Sage Publications, Inc.

Maroulis, S., Guimera, R., Petry, H., Stringer, M. J., Gomez, L. M., Amaral, L. A. N., \& Wilensky, U. (2010). Complex systems view of educational policy research. Science, 330(6000), 38-39.

Mason, M. (2009). Making educational development and change sustainable: Insights from complexity theory. International Journal of Educational Development, 29(2), 117-124.

Mehan, H. (2008). Engaging the sociological imagination: My journey into design research and public sociology. Anthropology \& Education Quarterly, 39(1), 77-91.

Mischen, P., \& Jackson, S. (2008). Connecting the dots: Applying complexity theory, knowledge management and social network analysis to policy implementation. Public Administration Quarterly, 32(3), 314-338. 
DAVID WHITE AND JAMES LEVIN

Mitchell, M. (2009). Complexity: A guided tour. New York, NY: Oxford University Press.

Morrison, K. (2002). School leadership and complexity theory. New York, NY: Routledge Falmer.

Oakes, J., \& Guiton, G. (1995). Matchmaking: The dynamics of high school tracking decisions. American Educational Research Journal, 32(1), 3-33.

O'Day, J. A. (2002). Complexity, accountability, and school improvement. Harvard Educational Review, 72(3), 239-329.

Parsad, B., \& Lewis, L. (2003). Remedial education at degree granting postsecondary institutions in Fall 2000 (NCES 2004-010). Washington, DC: National Center for Education Statistics.

Radford, M. (2007). Action research and the challenge of complexity. Cambridge Journal of Education, 37(2), 263278.

Schoenfeld, A. H. (2006). Design experiments. In J. L. Green, G. Camilli, \& P. B. Elmore (Eds.), Handbook of complementary methods in educational research (pp. 193-205). Mahwah, NJ: Lawrence Erlbaum Associates.

Stacey, R. D. (2001). Complex responsive processes: Learning and knowledge. London, UK: Routledge.

Stacey, R. (2007). Strategic management and organizational dynamics: The challenge of complexity (5th Ed.). Harlow, UK: Pearson Education Ltd.

Stringfield, S., \& Datnow, A. (2000). Working together for reliable school reform. The Journal of Education for Students Placed At Risk, Mahwah, NJ: Lawrence Erlbaum Associates.

Sui, W. (2008). Complexity theory and school reform. NASSP Bulletin, 92(2), 154-164.

Tobin, J. (1989). Visual anthropology and multivocal ethnography: A dialogical approach to Japanese preschool class size. Dialectical Anthropology, 13, 173-187.

Visual Understanding Environment (VUE) (2010). Version 3.0 beta3b11. Available online at http://vue.tufts.edu . Medford, MA: Tufts Academy Technology, Tufts University.

Wheatley, M. J. (1999). Leadership and the new science. San Francisco, CA: Berrett \& Koehler.

White, D. G. (2011). Using purposeful perturbations as a strategy for school reform: A design experiment at an alternative high school with low-performing students. Doctoral dissertation, University of California, San Diego. Available online at http://search.proquest.com/docview/884793036/abstract .

White, D. G., \& Levin, J. A. (2013). Navigating the turbulent waters of school reform guided by Complexity Theory. Paper presented at the 2013 American Educational Research Association meetings. San Francisco, CA. Available online at http://tinyurl.com/White-Levin-AERA2013-paper.

Wilensky, U. (1999). NetLogo. Available online at http://ccl.northwestern.edu/netlogo . Evanston, IL: Center for Connected Learning and Computer-Based Modeling, Northwestern University.

\section{Acknowledgments}

An earlier version of this paper was presented in a roundtable of papers organized by the SIG-Chaos \& Complexity Theories at the annual meeting of the American Educational Research Association, held in San Francisco CA in April 2013.

\section{About the Author/s}

James Levin is a Professor in the Department of Education Studies at the University of California, San Diego. His current research focuses on developing, evaluating, and utilizing multi-mediator models of learning at multiple levels including organizational and individual learning to improve learning and teaching. His contact email is jalevin@ucsd.edu.

David White is an adjunct professor in the physical science department at San Diego City College and a visiting scholar at the University of California, San Diego in the Department of Education Studies. His research focuses on inequality in education and school reform. His contact email is dwhite123@mindspring.com. 
(C) Copyright 2016. The authors, JAMES LEVIN AND DAVID WHITE, assign to the University of Alberta and other educational and non-profit institutions a non-exclusive license to use this document for personal use and in courses of instruction provided that the article is used in full and this copyright statement is reproduced. The authors also grant a non-exclusive license to the University of Alberta to publish this document in full on the World Wide Web, and for the document to be published on mirrors on the World Wide Web. Any other usage is prohibited without the express permission of the authors. 